\title{
AN INVESTIGATION OF STUDENTS' CONCEPTUAL UNDERSTANDING \\ IN RELATED SOPHOMORE TO GRADUATE-LEVEL \\ ENGINEERING AND MECHANICS \\ COURSES
}

By

DEVLIN BRADFORD MONTFORT

A thesis submitted in partial fulfillment of the requirements for the degree of

MASTER OF SCIENCE IN CIVIL ENGINEERING

WASHINGTON STATE UNIVERSITY

Department of Civil and Environmental Engineering

DECEMBER 2007 
To the Faculty of Washington State University:

The members of the Committee appointed to examine the thesis of DEVLIN BRADFORD MONTFORT find it satisfactory and recommend that it be accepted.

\section{Chair}




\section{ACKNOWLEDGMENT}

I think it is necessary to acknowledge the help and support I received from my department in completing this research. The faculty and students of the Department of Civil and Environmental Engineering are not only the subjects of my research, but the inspiration, audience and intended beneficiaries. 


\title{
AN INVESTIGATION OF STUDENTS' CONCEPTUAL UNDERSTANDING
}

IN RELATED SOPHOMORE TO GRADUATE-LEVEL

\author{
ENGINEERING AND MECHANICS
}

COURSES

\author{
Abstract \\ by Devlin Bradford Montfort \\ Washington State University \\ December 2007
}

Chair: Shane A. Brown

There is substantial evidence that many students graduating with engineering degrees do not possess a robust understanding of fundamental physical phenomena. One theoretical approach to correcting this lack of knowledge is based on addressing what Michelene Chi calls misconceptions. Misconceptions are the set of students' preexisting beliefs about physical phenomena which are persistent and preclude more correct understandings. Studies of students' conceptual understanding in engineering are rare, but researchers in the field of physics education have established a functional methodology for identifying and addressing misconceptions. The purpose of this study is to identify some key misconceptions in the field of engineering mechanics, while adapting the physic education methodology to engineering, and expanding it to address misconceptions holistically, as suggested by constructivist learning theories. Interviews with students from sophomore-, junior-, senior- and graduate-level mechanics and steel design courses revealed that students' conceptual understanding of stress and bending phenomena is not significantly different at the sophomore-level than the graduatelevel. Students generally expressed beliefs that stress flows like a liquid away from loadings, even when performing analyses or using equations that directly contradicted this belief. 


\section{TABLE OF CONTENTS}

LIST OF TABLES

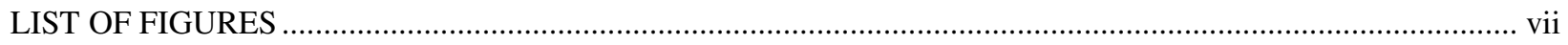

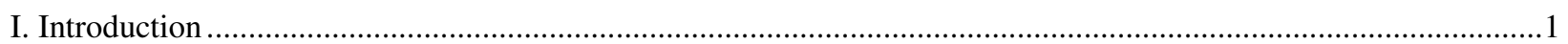

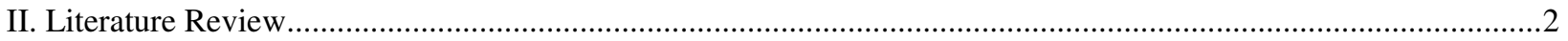

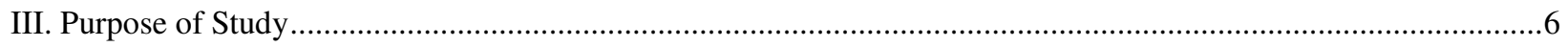

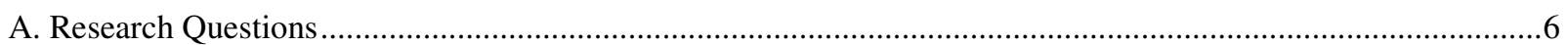

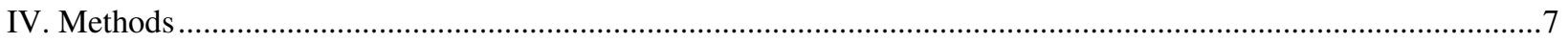

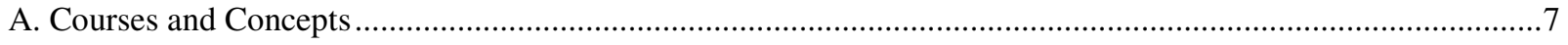

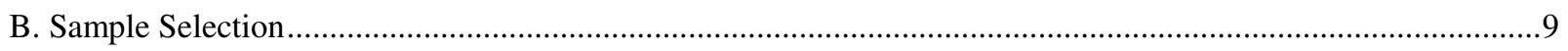

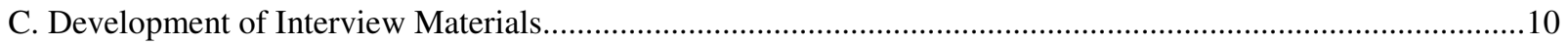

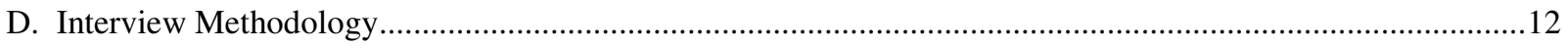

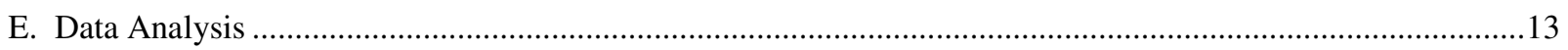

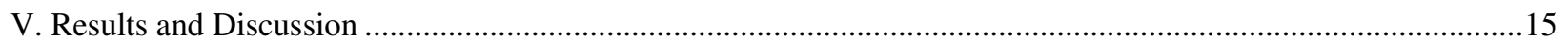

A. How does student conceptual understanding of bending differ between sophomores, juniors, seniors and

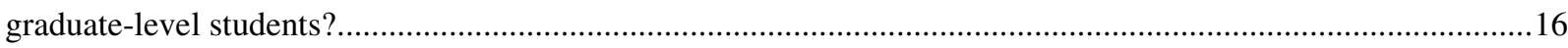

B. Do engineering students possess as low conceptual understanding of bending as would be assumed from theory and concept inventory results in other fields?

C. Which aspects of students' conceptual understanding (beliefs) of bending phenomena change as students progress through their undergraduate and Master's level courses?

D. Which beliefs are resistant to change in light of counter evidence presented in their courses?.......................25

E. Which of these beliefs can be considered misconceptions? .....................................................................28

F. Can students carry fundamental misconceptions with them through their engineering academic careers and still

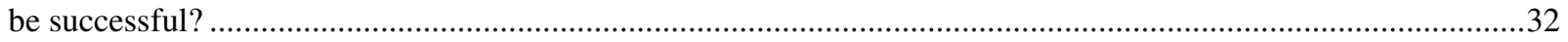

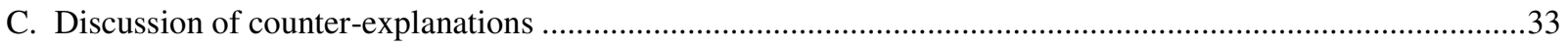

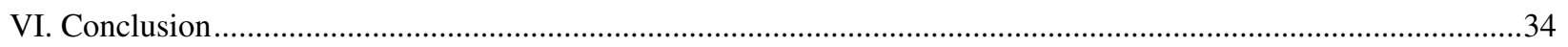

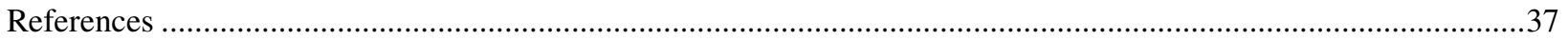

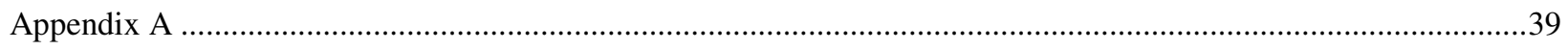




\section{LIST OF TABLES}

Table 1. Concepts covered in each course and correlated student year in the engineering program..........................

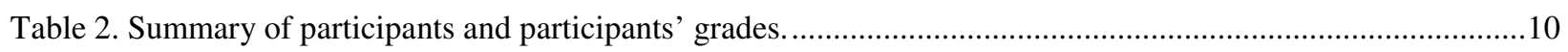

Table 3. Summary of interview question types and concepts covered. .............................................................12

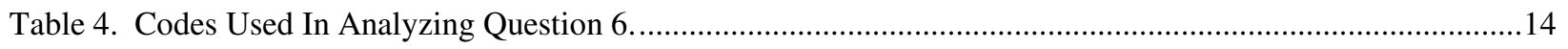

Table 5. Percentage of students in each course whose ranking matched the professors' (number of students in each

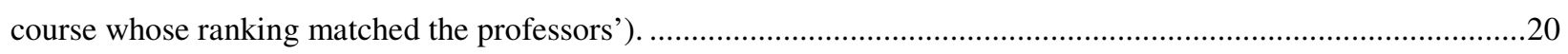

Table 6. Overall and component concepts investigated in student responses to each question...............................21

Table 7. Number of student statements indicating standard and alternative understandings of each question, and a

general characterization of their conceptual understanding of each question...........................................................21 


\section{LIST OF FIGURES}

Figure 1. Distribution of stresses in a simple bending beam. ........................................................................

Figure 2. Instructions and figures from the ranking task used in Question 3.......................................................17

Figure 3. Figures and instructions used for Question 2. ....................................................................................22

Figure 4. Instructions and figures from the ranking task used in Question 3.....................................................25

Figure 5. Instructions and figures from the ranking task used in Question 1. ......................................................26

Figure 6. Instructions and figures from the ranking task used in Question 5........................................................27

Figure 7. Representation of the misconception that stress flows out from loadings in bending beams....................29

Figure 8. Instructions and figures from the ranking task used in Question 6. .......................................................30

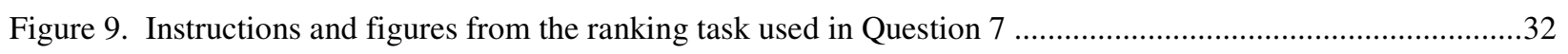

Figure 10. Instructions and figures from the ranking task used in Question 8 ......................................................32 


\section{INTRODUCTION}

Engineering educators are increasingly concerned with their students' understanding of engineering and the underlying physical sciences. Recent research indicates that despite high passing rates in most universities, most students do not understand their course content very deeply [for example see 1, and 2]. While this concern is new to engineering faculty, research in the teaching and learning of science and mathematics has been progressing for more than 20 years. Research, particularly in the field of physics education, has been progressing for more than 20 years, but problems and questions particular to engineering have only begun to be addressed. There are two main focii of research into the problem of how to increase student conceptual understanding. The first is directed toward creating curricular materials and proving their effectiveness, but the second is more concerned with determining how and why students do or do not develop conceptual understanding.

In order to discuss the subjective and unobservable phenomenon of deeper understanding, many researchers use the construct "conceptual understanding." This phrase is often used loosely to differentiate between students' abilities to perform calculations and their understanding of the significance of the calculations. In this study conceptual understanding of a particular topic is defined as the beliefs and framework used to acquire new knowledge or perform new applications of old knowledge in that topic. It can be thought of as an understanding of

the concepts underlying a calculation, including the context, purpose, necessary assumptions and range of reasonable values expected.

While students' computational abilities are relatively easy to develop with traditional homework and lecture, and easily assessed by standard exams, conceptual understanding is more difficult to develop and assess. Computational skill is predictable and is epitomized by familiarity with a standard process, but conceptual understanding is often applied in the form of intuitive leaps or in the structure of the solution itself. A body of research - again, largely in the physics education field - has grown around measuring students' conceptual understanding and developing curricular materials to improve it in specific topics. Due to the theoretical framework adopted in this research, most of these studies are performed within one course, or focus on one concept.

The purpose of this study is to begin to describe the general trends of how students in different school years understand a small set of related concepts. 


\section{LITERATURE REVIEW}

Concept inventories [2-4] suggest that most students do not truly understand the concepts covered in their science, technology, engineering and math (STEM). Concept inventories are tests that have been rigorously developed to measure students' conceptual understanding. The first of these was developed by Halloun and Hestenes to investigate freshmen knowledge of the most basic physics concepts, and was called the Force Concept Inventory (FCI) [4]. Halloun and Hestenes were surprised by students' extremely low scores on this test, because they formed the questions to be the most basic applications of the most basic physics principles. They expected most students to score nearly perfectly, because most students could perform calculations based on the Newtonian concepts tested in the FCI. However, they found that students consistently chose non-Newtonian explanations for common physical phenomena, and that “... student's initial qualitative, common sense beliefs about motion and causes have a large effect on performance in physics, but conventional instruction induces only a small change in those beliefs."

The FCI methodology and findings inspired the Foundation Coalition to develop concept inventories in thirteen different areas, including the engineering-specific field of strength of materials [5]. Results from this assessment have not been published, but preliminary results from the engineering-specific fields of statics [1] and thermodynamics [6], and the underlying theory imply that student conceptual understanding of engineering topics is expected to be as low as observed in other STEM areas.

Before discussing how researchers have responded to the revelation of students' low conceptual understanding, it is necessary to explain what conceptual understanding is and why it is important. Conceptual understanding is not a clearly defined construct, but most researchers compare it to intuition and contrast it to computational ability. Instructors often encounter this distinction in lecture when students who are successful performing complex calculations in their homework cannot answer "simple" questions about the nature of what is being studied. For example, a student might be able to calculate the longitudinal normal stresses developed due to bending, but would reason that no longitudinal stresses exist when asked to generally describe the stresses present. The phrase conceptual understanding is often used loosely to differentiate between students' abilities to perform calculations and their understanding of the significance of the calculations. More specific definitions depend on the researcher and the theoretical framework adopted. 
Contemporary theoretical frameworks adopted for examining student cognition are based on Jean Piaget's seminal work in cognitive development [7]. Piaget described learning as a developmental process in which people progress through standard stages of increasing understanding in order to internalize knowledge. Piaget identified six stages of cognitive development that he believed to be universal when learning [8]. Although new information is gained throughout the stages, each stage is defined by a particular perspective and method of obtaining and organizing information. At each stage a person gains a broader, more thorough and more flexible understanding.

He theorized that a person's knowledge is organized into categories. When people encounter new information they must either fit it into an existing category, or change the organization of their categories to fit the new knowledge. Piaget found that people were more likely to change new information to fit existing categories than to change or add categories. A classic example involves a child's first encounter with a cow. In the example, the child refers to the cow as a large dog, probably because it has the same basic body type. Eventually, the child will construct a new category called "cow," but in order to do that the child must become aware of the types of things that differentiate dogs from cows. This process requires much more work than simply using the existing category of dog. Piaget's approach was unique in its time because it implies that students' responses are usually valid in the context of their own knowledge.

Some cognitive psychologists [for examples see 9] described the process of changing or adding Piagetian categories as conceptual change. Chi and Roscoe [10] hypothesize that this process is difficult because of certain deeply-held beliefs that interfere with conceptual change in related subjects. These particular beliefs are defined as misconceptions. An example of a misconception from Chi and Roscoe's research is that some students believe that heat and cold behave like two separate fluids, flowing out of and filling objects up[10]. Even though this misconception is contradicted many times in a typical thermodynamics lecture, it is a part of the framework students use to make sense of the lectures, so they must either adjust what they hear to fit their beliefs, change their beliefs, or ignore the contradiction.

The University of Washington Physics Education Group (UW Physics Group) bases their very successful work in developing curricular materials to improve conceptual understanding on Piaget's developmental model of learning. They measure conceptual understanding using “... as an indicator of degree of understanding the extent to which a student's understanding corresponds to that of a physicist, ...[7]." This definition respects the validity of each student's representation, and aims to measure students' progress along Piaget's cognitive development by 
comparing them to an expert. This methodology was used to develop curricular materials for each topic in introductory physics. Misconceptions were identified in each topic—e.g. one-dimensional velocity [7], work-energy and impulse-momentum relations [11], or Archimedes' principle [12, 13]—and addressed separately. The materials were combined [14], but not interrelated. Materials developed to improve understanding of one topic were not assessed for their impact on related topics. For example, angular momentum was addressed using objects rolling down inclined planes and inherently involved the concepts of gravity, acceleration and friction, but these topics were not addressed in the angular momentum materials. This separation fits the Piagetian theoretical framework, where a student's progress in understanding a topic follows a linear pattern and curricular materials need to be designed to support that pattern.

In contrast, Jerome Bruner described learning as a complex process in which learners are constantly readjusting their existing knowledge and, more importantly, the relationships between the things that they know [15]. Bruner states that because people are constantly constructing their own understanding based on their experiences, and because their interpretation of their experiences is affected by their current understanding, the learning process cannot be simplified into a linear progression of stages. His work The Process of Education [15] was later classified as the beginning of constructivism, and along with Piaget, holds a central place in almost all currently accepted theories of learning.

Constructivism differs functionally from Piaget in that it emphasizes interrelated knowledge and does not assume standard stages of learning. Constructivist theory states that individuals interpret their experiences to create their own understanding of the world. Bruner's concept of education then, depends on facilitating student experiences so that they can construct complex, useful understandings of STEM fields. In order to do this Bruner focuses on what he calls the structure of a field. He explains, "Grasping the structure of a subject is understanding it in a way that permits many other things to be related to it meaningfully. To learn structure, in short, is to learn how things are related" [15]. Structure is not limited to knowledge of how facts and equations are related, but also includes an epistemological perspective on how knowledge is created and organized within a subject. He writes "[m]astery of the fundamental ideas of a field involves not only the grasping of general principles, but also the development of an attitude toward learning and inquiry, toward guessing and hunches, toward the possibility of solving problems on one's own." 
Constructivism implies that an engineer's perspective on how knowledge of physics is created may differ significantly from a physicist's perspective, both of which would differ from most students' perspectives. More importantly, expert-novice theory extrapolates this implication and finds that experts in a field not only construct knowledge differently from novices, but actually perceive phenomena differently [16].

Bruner's refinements of Piaget's theory require adjustments to the methodology used to study conceptual understanding. The more concrete changes are to adapt the methods used by physics educators to engineering: because the structure of each subject is different, the definition and expectations of student conceptual understanding will be different. Applying constructivism to the study of student conceptual understanding requires more abstract changes as well. In general, the research must make even fewer assumptions about the state of the student's understanding. Because true learning involves relating all existing knowledge to what is being learned, it no longer makes sense to examine single concepts, or to examine them at a single point. Students are constructing their understandings of phenomena throughout their academic careers. The UW Physics Group has demonstrated success in addressing student difficulties in individual concepts, but it is still unknown how these incremental increases in conceptual understanding help the students' overall understanding of physics, or if the demonstrated improvement in the basic concepts will help students acquire more complex ones.

Experts in engineering agree that concepts taught in the sophomore year are required to learn concepts in the senior year. This may be true from the expert's perspective, but it is also possible that students need the concepts from their senior year to construct an understanding of the sophomore concepts. Our division of concepts-for example, defining the concept of buckling as a part of the concept of failure-probably does not match students' divisions of the same information, especially when they are learning and undergoing conceptual change [10].

Following a constructivist framework, in this study conceptual understanding of a particular topic is defined as the beliefs and framework used to accomodate new knowledge or perform new applications of old knowledge in that topic. It can be thought of as an understanding of the concepts underlying a calculation, including the context, purpose, necessary assumptions and range of reasonable values expected.

The persistence of low conceptual understanding through college cannot be attributed to concepts not being taught, or being taught improperly $[4,10,17-20]$. There is a complex cognitive phenomenon related to students' beliefs that interferes with the learning of certain subjects. The best current theories to explain this phenomenon agree that people learn by constructing their own context for understanding [15], and that previous knowledge has a 
large effect on learning [10]. Previous methods of addressing student conceptual understanding guide students through predetermined stages of understanding, and do not reflect the complexity of how individual students will construct their understanding of the concepts' interrelations through their collegiate career.

The existing research in student conceptual understanding is sparse in engineering-specific content areas. Beyond this basic lack, the existing methodologies address individual concepts in the context of single courses. This approach does not take into account the complexity of the process of constructing knowledge.

\section{PuRPoSe OF STUdy}

The purpose of this study is to begin to investigate how students construct their conceptual understanding throughout the engineering curriculum by comparing "snapshots" of student reasoning in different years. The word "snapshot" is used to differentiate this research from a longitudinal study: this is not an investigation of how individual students develop their conceptual understanding, but a look at how the general trends of conceptual understanding differ between school-years. This study is the beginning of a line of inquiry that will eventually accomplish the following broader goal: to understand how students' misconceptions develop through their engineering academic careers including an understanding of which misconceptions students develop at which points in their careers and to use this understanding to modify the engineering curriculum to most efficiently help students

develop a robust conceptual understanding of mechanics of materials. This purpose translates into three research questions.

\section{A. Research Questions}

This study will answer the following questions and sub-questions:

1. How does student conceptual understanding of bending differ among sophomores, juniors, seniors and graduate-level students?

1.a. Do engineering students possess low conceptual understanding of bending, as would be assumed from theory and concept inventory results in other fields?

1.b. Which aspects of students' conceptual understanding of (beliefs about) bending phenomena change as students progress through their undergraduate and Master's level courses?

2. Which beliefs are resistant to change in light of counter evidence presented in their courses?

2.a. Which of these beliefs can be considered misconceptions?

2.b. Can students carry fundamental misconceptions with them through their engineering academic careers and still be successful? 


\section{METHODS}

In order to achieve these goals and answer these questions, qualitative interview and analysis methodologies were implemented. It is important to note that qualitative researchers use different methods to describe the quality of research [for a more complete description of qualitative research methods in use in engineering education see 21, 22]. The two primary dimensions of measurement are credibility and dependability. Credibility is parallel to validity, and refers to the "relative truth value of qualitative findings and interpretations" [21]. A study's credibility is built on the strength of the methods and the expertise of the researcher [23]. Dependability is similar to reliability, and relates to how similar the results of a qualitative study would be if performed again, or by different people. A primary source of both dependability and credibility in research methods is through the use of triangulation—forming conclusions only when multiple data sources agree [23].

Interviews were conducted with approximately 5 students from the Spring 2007 semesters of each of the following courses: $\mathrm{MoM}_{2}-$ Mechanics of Materials; Struct $_{3}$ - Introduction to Structures; Steel $_{4}-$ Structural Steel Design and; $A d v-$ Steel $_{5}$ - Advanced Structural Steel Design. These interviews provide a snapshot of the student participants: this is not a longitudinal study. The interviews were structured around a set of four concepts that are

traditionally believed to build upon each other. This means that experts see the fourth concept as being mostly constructed from the previous three concepts. A brief discussion of the four concepts - labeled stress, buckling, bending and local buckling of the flange of a beam - will follow in the Results section. The interviews were analyzed using the constant comparative method for student conceptual understanding, and then analyzed to compare between classes and between concepts for individual students.

\section{A. Courses and Concepts}

The concept of bending was chosen as the focus of the research. The phenomenon of local buckling of the flange was chosen as a complex, real-world application of the concept of bending, which necessitated the inclusion of the concept of buckling in order to prevent conceptual understanding of buckling from being an intervening variable. The specific courses were chosen because all four share the same basic concepts of stress, buckling and bending, but their application becomes more and more complex. Also, because the first two courses are required for all civil engineers and the structural engineering emphasis is the most popular in this department, the classes would be sufficiently large to allow truly purposeful sampling. 
These desirable characteristics in the courses guided the researchers to choose related concepts from those courses. Through interviews with an expert structural engineering faculty member who has taught all of these courses, and analyzing the content of the Strength of Materials Concept Inventory [5], the researchers chose bending as a focus because of persistent student difficulty and their previous work with this concept $[24,25]$. The concept of buckling was added because fewer students were expected to have difficulty with it, and to allow the interview to conclude with the concept of local buckling in the flange. Including local buckling provided the researchers with more data to use in triangulating their assessment of the students' understanding of buckling and bending. Approximately half of the students interviewed had not discussed local buckling in their classes, and their responses to this question provide the researchers a baseline with which to analyze their responses to the other questions. The analysis of the students' responses to this concept with which they have no experience will help sort through the noise of personality, communication style and self-confidence to get to the signal of conceptual understanding.

$M o M_{2}$ is a sophomore class, and is typically one of the first engineering content classes taken by civil and mechanical engineers. It introduces students to the concepts of stress, strain and the design of structural members. Struct $_{3}$ is also required for all civil engineers, and is the last course on structural engineering that many students will take. Starting with the analysis techniques learned in $\mathrm{MoM}_{2}$, Struct 3 covers the design and analysis of basic structural elements, including columns, beams and frames. Steel ${ }_{4}$ is a design elective course taken almost exclusively by senior civil engineers who have chosen to emphasize structures in their undergraduate coursework. It covers the intricacies of designing steel elements, including columns, beams and local buckling. Adv-Steel ${ }_{5}$ is a graduate-level course taken mostly by first-year graduate students on the structural engineering track. It covers more complicated analysis and design topics for types of steel structures, including combined loading, plastic collapse analysis and local buckling analyses. Table 1 below summarizes the course descriptions.

In the Spring 2007 semester, $M o M_{2}$ was taught by a professor whose research emphasis is in environmental engineering, and had been teaching for approximately one year. Struct 3 was taught by a structures professor who had been teaching for approximately 19 years, and had been teaching in his current position for about 13 years. Both $\mathrm{Steel}_{4}$ and $\mathrm{Adv}$-Steel ${ }_{5}$ was taught by a structural professor who had been teaching for approximately10 years, and was involved in developing the interview materials for this study. 


\begin{tabular}{cccccc}
\hline Course & Abbreviation & Student Grade & Buckling & Bending & Local Buckling \\
\hline $\begin{array}{c}\text { Mechanics of } \\
\text { Materials }\end{array}$ & MoM $_{2}$ & Sophomore & $\mathrm{X}^{*}$ & $\mathrm{X}$ & \\
$\begin{array}{c}\text { Introduction to } \\
\text { Structures }\end{array}$ & Struct $_{3}$ & Junior & $\mathrm{X}$ & $\mathrm{X}$ & \\
$\begin{array}{c}\text { Structural Steel } \\
\text { Design }\end{array}$ & Steel $_{4}$ & Senior & $\mathrm{X}$ & $\mathrm{X}$ & $\mathrm{X}$ \\
$\begin{array}{c}\text { Advanced } \\
\text { Structural Steel } \\
\text { Design }\end{array}$ & Adv-Steel & & & $\mathrm{X}$ & $\mathrm{X}$ \\
\hline These concepts are & Graduate & $\mathrm{X}$ & &
\end{tabular}

* These concepts are covered briefly in the indicated courses.

Table 1. Concepts covered in each course and correlated student year in the engineering program. The subscript numbers in the abbreviations indicate student year: 2 for sophomores, 3 for juniors, etc.

Although the professors for these classes are diverse in ways that could be expected to affect their effectiveness in teaching these courses, this should not affect the credibility of this study. As Halloun, Hestenes and others have shown $[7,17,18,26]$, traditional instruction does not affect students' conceptual understanding as much as their previous beliefs, and while all three professors are successful instructors, none use the innovative, inductive methods shown to improve conceptual understanding. Additionally, the differences in instructor quality would affect the analysis of student responses within the same classes, as well as across them. For example, some students in the graduate-level course have come from other universities, and some of the students in the senior-level course may have had different instructors for $\mathrm{MoM}_{2}$. The instructor is an intervening variable in this study, but the sample was chosen such that the effects of instructor quality would be non-directional: the random variations would not bias the analysis even if there was a strong correlation between instructor and conceptual understanding because the analysis is between classes while the variation is both between and within the classes.

\section{B. Sample Selection}

Critical case sampling was used to achieve the research goals. Critical case sampling is a form of purposeful sampling that allows directional inferences about broader populations [23]. A critical case is one where something is either most likely or least likely to be found, so that the reasoning "if it is true for them, it must be true for others," can be used. In this study the professors were asked to select from among the "4-8 best students in your class." The professors asked the students if they would be willing to participate, and set up a contact with the researcher for those who were. Of the 27 who were initially contacted, 21 participated in interviews. Table 2 below presents 
general information about these students, summarized by course. The GPA's and grades in the course were selfreported during the interviews, and are recorded here on a four-point scale.

\begin{tabular}{ccccc}
\hline Course & Number of Participants & Average GPA & $\begin{array}{c}\text { Expected Grade in } \\
\text { Course }\end{array}$ \\
\hline MoM $_{2}$ & 4 & 3.3 & 3.5 \\
Struct $_{3}$ & 7 & 3.6 & 3.8 \\
Steel $_{4}$ & 6 & 3.5 & 3.8 \\
Adv-Steel & 4 & 3.9 & 3.9 \\
\hline
\end{tabular}

Table 2. Summary of participants and participants' grades.

The non-specific term "best" was used intentionally, and is central to this selection being considered a critical case. In separate discussions with each of the professors involved, the key criteria involved in choosing the students appeared to be primarily 1) interaction with the professor and peers, 2) exam and homework quality and scores, and 3) overall academic performance, based either on knowledge of the student's grade-point average (GPA) or anecdotal evidence from class. Because this study is investigating the effect of the degree program on students' conceptual understanding, these students who are most engaged and successful in the program form a critical case. If these students' conceptual understanding does not increase through the degree program, it is reasonable to assume that most students' does not.

\section{Development of Interview Materials}

Following McDermott the interviews were based on Piaget's clinical interviewing method [7]. Ginsburg describes exploration and hypothesis testing as key elements in an interview designed to describe the interviewee's perspective with limited affect from the interviewer's bias [27]. Exploration is key because the interviewer cannot guess what the interviewee knows, or how that knowledge is organized. For example, a mechanics of materials instructor may view the course as examining three main concepts, and ask a question like "what do you think are the main concepts of this course?" The student may view the course as a series of loosely-linked procedures, and though this belief would be important to the instructor, it could not be discovered without more exploration. Exploration was incorporated into the interviews primarily in Questions 1 and 2 (see Figures 5 and 3 below, respectively), but also as a part of each question. The first two questions were very general, and students were asked to respond immediately to the prompt when they had finished reading. These first responses and the follow-up questions served as a form of exploration. 
Hypothesis testing is a form of triangulating data. When the interviewer forms a hypothesis about the interviewee's perspective, it should be tested with follow-up questions. Again, this was incorporated into the questions themselves: each concept of interest is repeated in at least two questions. Additionally, students were asked to repeat their reasoning for each ranking decision in multiple ways. For example, if a student explained that $\mathrm{a}$ is greater than $\mathrm{b}$ because a has more area, they would then be asked to explain why they ranked $\mathrm{c}$ as greater than $\mathrm{d}$.

The researcher performing the interviews had some previous experience in clinical interviewing, and had performed fewer than ten previous to this study. This lack of experience, however, was identified and accounted for in the research design. Using the guidelines presented in Ginsburg's Entering the Child's Mind, and the example of Piaget's motion tasks [28], the interviews were structured by the interviewer and coauthor (an experienced clinical interviewer) around a set of problems with a few standard questions. Further questions were used to encourage students to think aloud, to clarify student statements, and to test the strength of student statements. This structured format limited the amount of improvisation required by the inexperienced researcher, and facilitated the exploration and hypothesis testing that is so valuable in the analysis stage. Furthermore, the analysis was also designed to account for the interviewer's lack of training, as will be discussed in the Data Analysis section to follow.

Ranking tasks were used to allow the researcher to observe the students constructing understanding. A ranking task is a quick way to assess or improve a student's understanding [29]. Ranking tasks require students to compare features of physical situations without being given equations or the context of a specific topic. For example, a ranking task used in this study shows six identical beams under different loadings, and requires students to rank the normal stress due to bending at a specific point from highest to least. This example was designed to assess student understanding of normal stress due to bending. For convenience, figures showing the ranking tasks developed will be included in the Results and Discussion section.

Individuals construct the structure of a subject when applying it to new but related topics $[15,16,30]$. Because the students were not familiar with ranking tasks, and probably had not been asked to use their knowledge to compare similar situations before, they were constructing understanding during the interviews. For example, knowing the bending stress equation is sufficient to be successful in most $\mathrm{MoM}_{2}$ and $\mathrm{Struct}_{3}$ homework problems on the topic, but not every student who referred to this equation was able to apply it to the ranking tasks. Furthermore, students who were able to apply this equation weren't judged to have displayed conceptual understanding unless they could also explain the terms of their equation and why they used it. 
Seven ranking tasks were developed, and an additional page of pre-defined questions about stress gave the students eight pages of questions, which they completed in 50-80 minutes. The first ranking task (Question 1 below) and page of open-ended questions (Question 2 below) were designed to elicit the students' conceptual understanding of stress. The second and third ranking tasks (Questions 3 and 4 below) were designed to discuss buckling, and the fourth, fifth and sixth (Questions 5,6 and 7 below) dealt with bending. The final ranking task (Question 8 below) concerned local buckling in the flange. The interview packet was revised after the first two interviews, so those two students responded to an additional question about stress and did not respond to question 4 . The revised interview packets were validated through interviews with the instructors from $\mathrm{MoM}_{2}, \mathrm{Struct}_{3}, \mathrm{Steel}_{4}$ and $A d v-$ Steel $_{5}$.

Table 3 below summarizes the interview packet and how each page will be referenced throughout this paper. Each question contained a brief description of the figures, instructions, figures and questions. The ranking tasks all provided numbered spaces for students to enter their rankings, and the following two questions with space for handwritten answers: 1) Please describe your reasoning; 2) What key equations or properties did you use to make your ranking. A blank copy of the final interview packet is included in Appendix A.

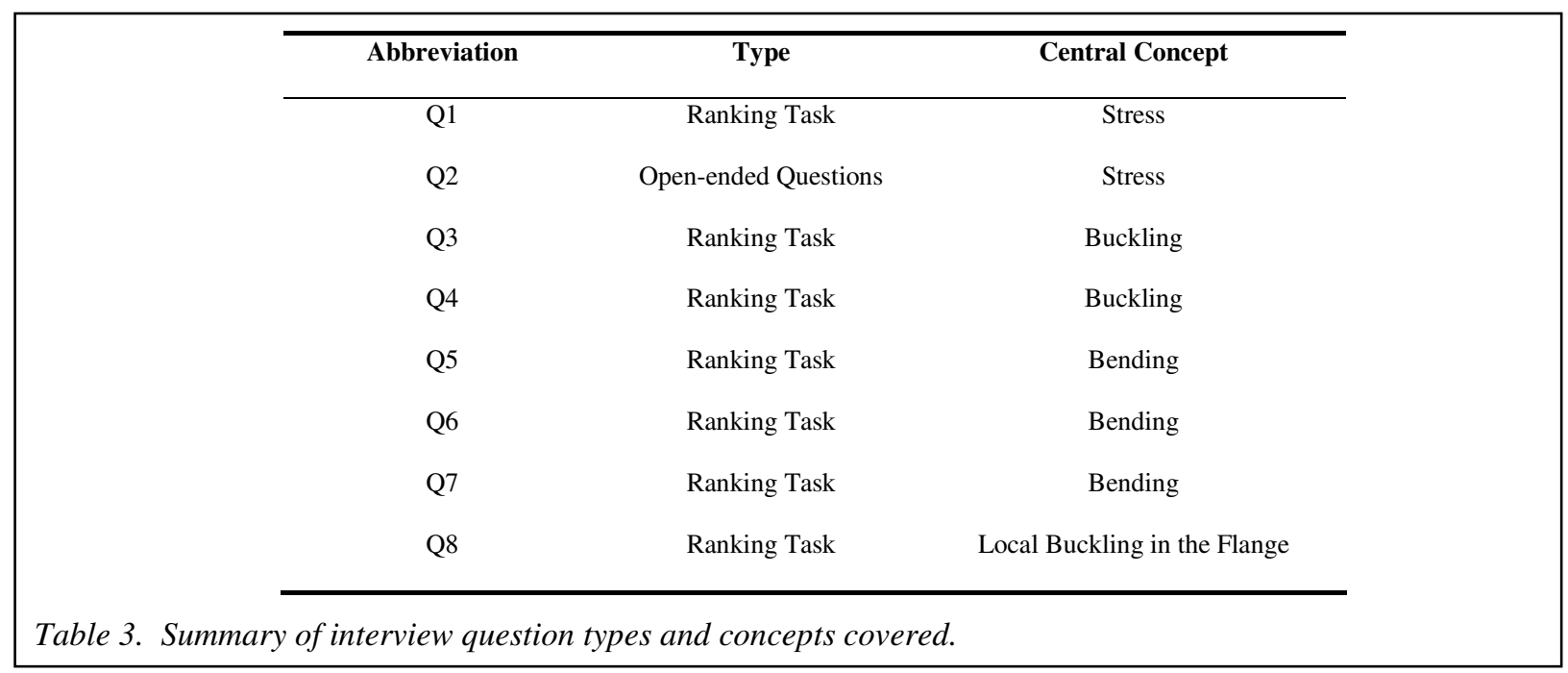

\section{Interview Methodology}

Because the interviewer had previous interactions with some students, either as a teaching assistant or as a classmate, the social effects of the interviewer were biased. The interviewer attempted to address this issue by taking a few minutes for introductions and discussion before interviews with students whom he had not met, and by explicitly addressing the issue with students he had met while going over the informed consent form. The discomfort of being interviewed, video and audio taped by a peer in a perceived position of power was addressed 
directly in each interview. The interviewer took time between most questions to check in with the participant, and to attempt to encourage or relax them. The general discomfort most students felt with the circumstances was more apparent in the interviews than any differences in discomfort observed between known and unknown students. Finally, because the interviewer had previous contact with 2 or 3 students in each course, the analysis between classes will remain credible and dependable.

The student interviews were audio and video recorded, and the interview packets were collected to record student notes and sketches. After each interview, notes were taken describing the interviewer's general impression of the student's comfort in the interview, level of effort and overall understanding of the topics covered. General notes to guide analysis were recorded periodically through the interviewing process. The instructor for $\mathrm{Steel}_{4}$ and $A d v-$ Steel $_{5}$ was interviewed and audio recorded in order to serve as the expert to which the students were compared.

Each interview was transcribed from the audio recording in the order in which it was conducted. All but two interviewers were transcribed by the primary researcher. Review of the transcrips with the video recordings and the students' notes was used to clarify non-specific statements (e.g. "I think this one is bigger than this one") and misstatements (e.g. a student says "c is more than e" when he or she actually means the reverse).

\section{E. Data Analysis}

The data was analyzed using the constant comparative method. Briefly, this method of analysis involves comparing new pieces of data with all existing data trends [31]. If the new data do not fit into existing trends, a new trend is hypothesized and all existing data are reanalyzed to look for occurrences of the new trend. In this study, the smallest unit of data is a student statement. A statement is defined as a group of words intended by the speaker to convey an idea. For example, the word "yes" would constitute a statement if the student was responding to a closed

question. Because the purpose of the analysis was to describe student reasoning, the trends being developed were alternative explanations of bending or buckling phenomena.

These transcriptions were coded in two phases using a qualitative analysis software program [32]. The first phase was a mostly unstructured categorization of student statements. This categorization was unstructured in that it was not intended to achieve the particular goals of this study, but instead to identify what types of statements students made frequently.

The next phase of coding was more analytical. This phase—sometimes called "pattern coding" [33]—consisted of identifying and coding patterns in the student statements. The patterns had been identified during the 
interviewing and transcribing, and this phase just verified and recorded (or discarded) those patterns. In this phase the general notes made during the interviews were also addressed by comparison to the actual data. The second phase was specifically oriented to identifying and coding examples of correct and incorrect reasoning. For example, in the normal stress due to bending example described above (see Figure 1 or P6 in Appendix 1), seven codes were used to describe student reasoning. These codes are included as an example in Table 4 below. In Table 4 the number of quotes is included to provide an example of the number of instances used for each code, but this value should not be given too much attention. If a student made a strong statement that revealed confusion about the cause of bending stress, and then referred back to it throughout the rest of the interview, for example, that would probably only be coded once (or count as one quote) as "[0.6] Causes of Bending." If another student, however, frequently checked their reasoning, or made strong, specific statements about what they knew and didn't know about the causes of bending stress, each of those statements would be coded. The coding facilitates, but does not complete, the analysis.

\begin{tabular}{|c|c|c|c|}
\hline Code Name & Comment & Quotes & $\begin{array}{l}\text { Students } \\
\text { Quoted }\end{array}$ \\
\hline [0.6] Causes of Bending & Confusion about what causes bending stress or conceptual meaning of MC over I. & 11 & 7 \\
\hline [0.6] Further from Load & $\begin{array}{l}\text { When students use distance from the load in their reasoning without reference to the } \\
\text { moment diagram. }\end{array}$ & 16 & 8 \\
\hline [0.6] Normal Stress & When confusion about what normal stresses are interferes with reasoning. & 29 & 12 \\
\hline $\begin{array}{l}\text { [0.6] Memorized } \\
\text { Process }\end{array}$ & $\begin{array}{l}\text { When students proceed through analysis using a memorized process or rely on equation } \\
\text { without conceptual checks. }\end{array}$ & 6 & 4 \\
\hline $\begin{array}{l}\text { [1.6] Moment } \\
\text { Distribution }\end{array}$ & $\begin{array}{c}\text { When students use moment diagram in reasoning out of horizontal distribution of normal } \\
\text { stresses }\end{array}$ & 11 & 10 \\
\hline [1.6] Conceptual & When students use conceptual reasoning or verification in their ranking. & 11 & 6 \\
\hline $\begin{array}{l}\text { [1.6] Vertical } \\
\text { Distribution }\end{array}$ & When students identify and use vertical distribution of normal stresses in a bending beam. & 16 & 10 \\
\hline
\end{tabular}

Table 4. Codes Used In Analyzing Question 6.

When all the transcriptions were coded in both these phases, there were approximately 90 codes and 1400 quotations. In order to summarize and begin to analyze this data, the primary researcher created a very loose point system for the understanding of each question. Each question was worth three points, and each point was assigned to a specific component concept. These component concepts were not intended to capture the complete complexity 
of the problem, but only to represent the concepts that would be necessary for the local buckling question at the end. The points were developed in part from the primary researcher's own knowledge of the questions, but for the most part came from the analysis of the expert's response to the question. Each student's responses were then scored and compared. This stage of the analysis did not provide any meaningful comparisons, but allowed the researcher to quickly compare student performance using simple spreadsheet software.

After a period of exploration using the loose student scores, the research questions were specifically answered. This process involved using the score data to generate a hypothetical answer, and then using the coded transcripts to verify or disprove that hypothesis. As shown in Table 4, many of the codes used are based on a subjective analysis of a particular statement. In some cases opposing codes can be found in the same interview, and the number of codes a student receives is dependent on their talkativeness as much as their level of understanding. These shortcomings are integral in the analysis. This analysis is dependent on trends and patterns, and therefore should not attach much significance to any single code or statement. The credibility in this analysis is maintained by only making statements or conclusions that can be strongly supported by the data in multiple ways. For example, a student could not be described as lacking in understanding of buckling unless they could be quoted exhibiting serious confusion in Questions 3, 4 and 8 concerning the basic concept of buckling.

Much of the credibility and dependability of this analysis, then, depends on the researcher. The primary researcher would need to have sufficient knowledge of the subject matter, the interviewing procedure, and the analysis methods in order for this study to truly be credible and dependable. The primary researcher, however, was supported in all methodological decisions by the co-author Dr. Shane Brown, a credible expert in qualitative research in the field of engineering education, and Dr. David Pollock, an expert structural engineer, instructor and researcher in the field of timber structural mechanics.

\section{RESULTS AND DISCUSSION}

The results will be organized under each research question and sub-question. The most probable counterexplanations will be addressed as a separate sub-section at the end of this section. To facilitate the discussion, Figure 1 below shows the stresses and internal moment diagrams present in a simple bending beam. The key features of this loading situation—often used to introduce bending phenomena to students—are that the internal moment in the beam increases linearly from zero at the ends to a maximum value in the center, and that the normal stresses caused by that moment vary vertically thought the cross-section. The vertical distribution of stresses is also 
linear and symmetrical about the neutral axis (in this case the neutral axis is at the center of the cross-section). In bending, one side of the beam experiences compressive normal stresses and the opposite side experiences tensile stresses of an equal magnitude. Questions 6 and 7 in the interviews dealt exclusively with this situation, and Questions 2, 5 and 8 included some of the same concepts.

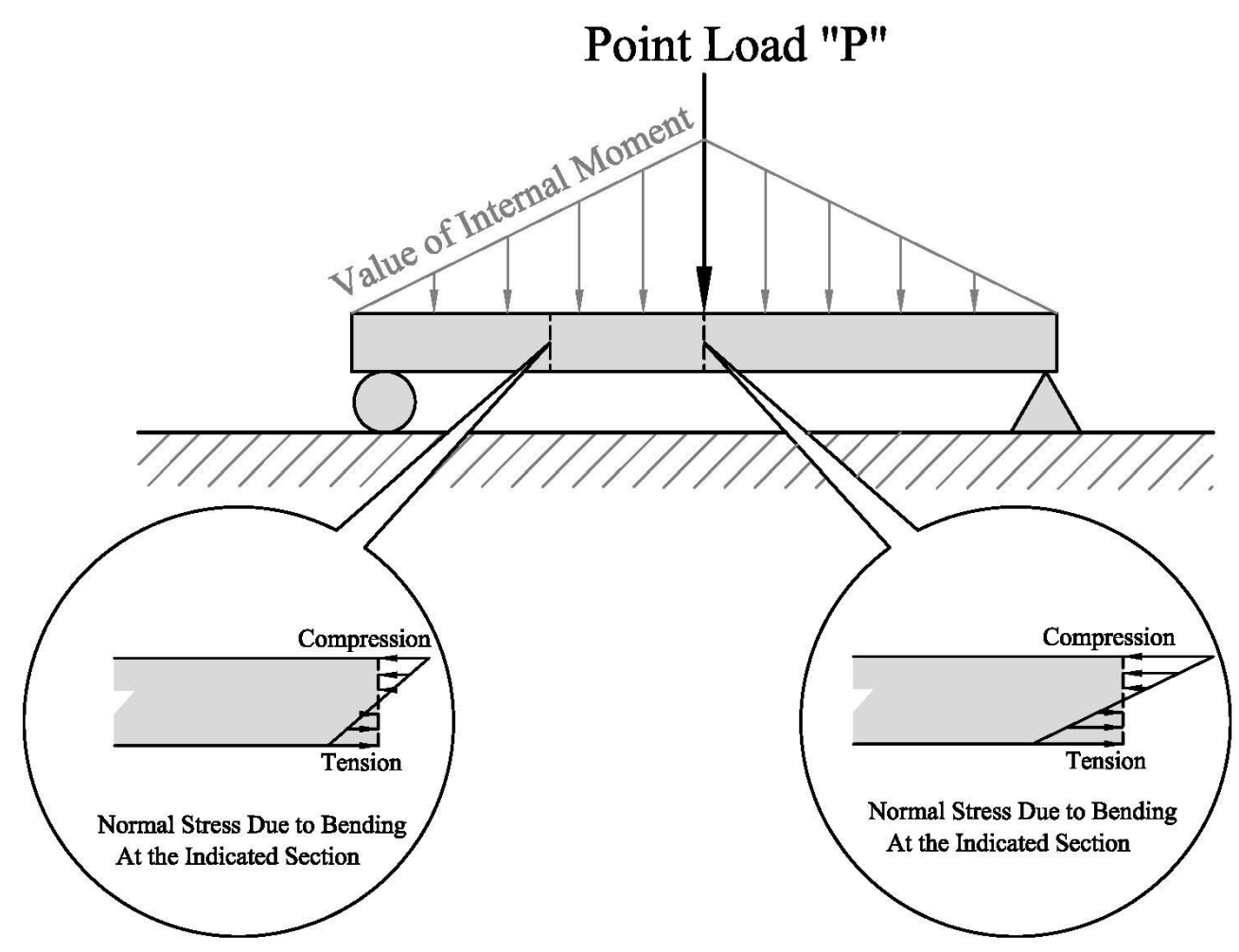

Figure 1. Distribution of stresses in a simple bending beam.

\section{A. How does student conceptual understanding of bending differ between sophomores, juniors, seniors and graduate-level students?}

There were no significant differences between classes in how students approached the interview questions.

Students reasoned in different ways, but the way a student reasoned and the class they had most recently taken did not appear to be related. In general, students attempted to compare interview questions to previously completed homework problems. The graduate students used the same basic approach, but were more often able to reason through how the equations they remembered would effect the interview questions. For example, in response to Question 3 most students (about three-quarters) made statements identifying the weak axis as contributing to 
buckling. More than half of the undergraduate students, however, also made statements that cross-sectional area contributed to buckling, indicating that they did not understand the concept of the weak axis in the context of buckling. None of the graduate students included cross-sectional area in their analysis. Question 3, not including the space left for student responses, is shown below in Figure 2.

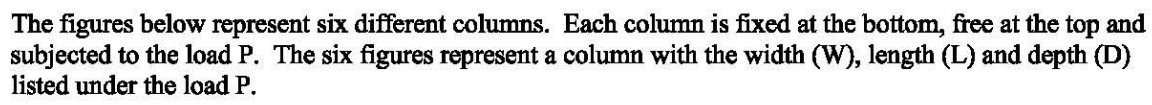

The figures below represent six different columns. Each column is fixed at the bottom, free at the top and subjected to the load $P$. The six figures represent a column with the width (W), length (L) and depth (D) listed under the load $P$.
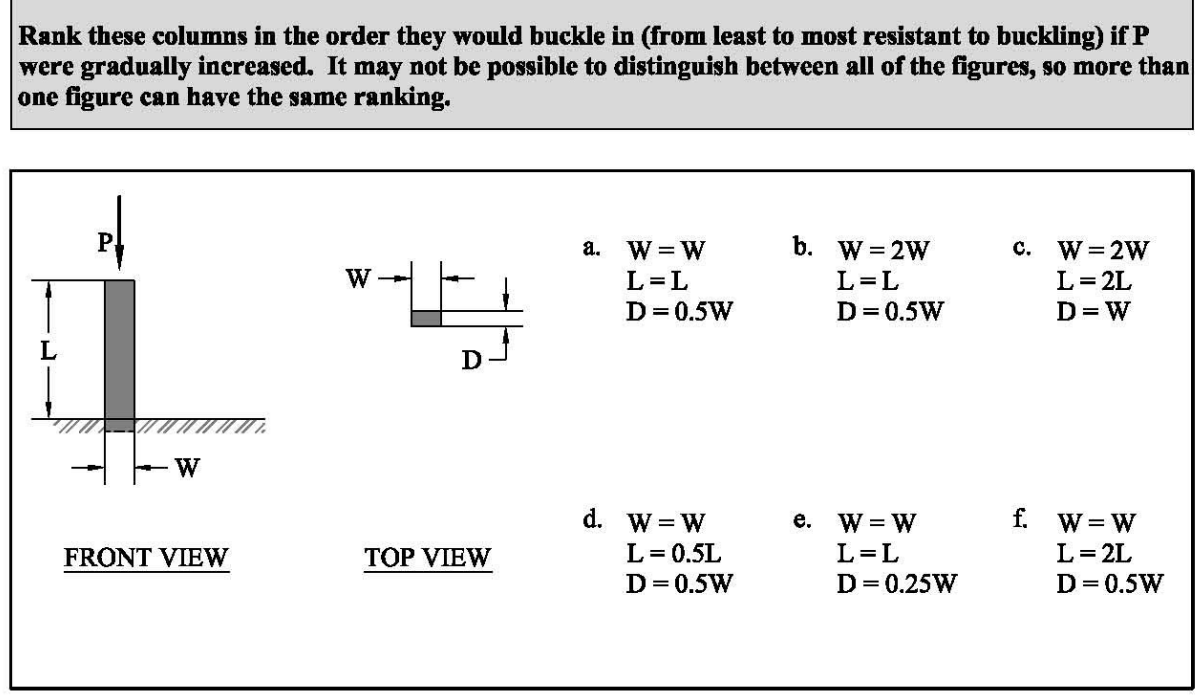

Figure 2. Instructions and figures from the ranking task used in Question 3. Note that in most interviews it was necessary to clarify that when " $W$ " appears on the right of the equals sign it refers to the original dimension.

All but one of the Steel $_{4}$ students who identified the weak axis also used cross-sectional area in their reasoning.

For example, Lena reasoned that figure f (shown above in Figure 2) would be the most susceptible to buckling because:

Lena: Uh, it's the longest, and...has the smallest width.

Montfort: Okay.

Lena: And, a small depth, also...well...kinda small.

Montfort: [pause] Okay.

Lena: [pause] And then. [very long pause] Probably this one?

Montfort: e?

Lena: Yeah. 
Montfort: okay. Why's that?

Lena: [pause] Uhm. [long pause] Actually, I'm not sh...it has s small depth, and, you know I think that'll make it more susceptible to buckling.

Montfort: Okay.

Lena: Kinda doesn't have as big of a cross-section.

In general, the Steel $_{4}$ students had more difficulty reconciling their beliefs than students in other classes. For all of the ranking questions except for two, more Steel $_{4}$ students were unable to choose a ranking than any of the other classes. This does not mean that the Steel $_{4}$ students showed less knowledge: for example, in Question 3 a higher proportion of $\mathrm{Steel}_{4}$ students identified the weak axis and length as the key contributors to buckling and used an appropriate buckling equation than in any of the other undergraduate classes. Most of those students, however, were unable to reconcile that knowledge with their intuition that cross-sectional area is important in failure. For example, Lena later said, “...Uhm, these are both...this would be susceptible, I think, to buckling because of the length....But I don't know how much, cuz I don't know, cuz it, the W has been doubled. So. But I still think, because of the length." Hank was also unable to reconcile his two beliefs that both length and cross-sectional area of the column mattered to buckling, saying:

Hank: Uh, because the area is the greatest? Oh, crap, nevermind. You caught me in my own logic swing. No, that wouldn't be right. Because the length gets higher, and like I just said if the length is higher, or if the length is greater, then it's more likely to buckle...[sigh] So you have twice the length, but twice the area. [pause] So there has to be something...that determines which is more important. [laughs],

and eventually “... I don't think I'm gonna have any other, epiphanies or deductions about it, uh... in the time allotted but, well let's face it even if there was more time I probably wouldn't. [laughs]"

Although this trend seems counter-intuitive, it could be predicted from theory. The process of addressing misconceptions is called conceptual change, and is a difficult process that requires students to reevaluate many of their beliefs about the subject $[9,10,34]$. Because the graduate students interviewed showed higher conceptual 
understanding than the undergraduates, it can be inferred that conceptual change has occurred. The Steel $\mathrm{s}_{4}$ students' inability to apply their knowledge in context supports the inference that they are undergoing conceptual change.

The students from $A d v-$ Steel $_{5}$ appeared more confident and methodical. They used equations more freely, and engaged in self-checks more frequently than the other students, but still rarely. The undergraduates would often refer to their lack of knowledge when first presented with a question, often saying "I dunno," or "These are hard," but the graduate students more often explained their hesitation in terms of communication, saying, "How could I explain this," or asking questions about what answer was expected. For example Rita, a graduate student, used the following reasoning to decide whether length or geometry were more important in Question 3.

Rita: Pi-squared E I over K L over R-squared. I think is the quick critical buckling stress? Uhm. Montfort: Okay.

Rita: And in the, Euler...buckling...stress is what I think it is. Uhm. And, the, k-factor is, uh, an effective length factor depending on what the fixity is. They all have the same fixity, so they're all gonna have the same k-factor, so, basically, uh... since...the, the mathematical explanation, I mean I know that the longer column's buckle first with the same cross-section

Montfort: $\mathrm{mm}-\mathrm{hm}$.

Rita: but as far as the mathematical explanation, L's in the denominator, the bigger L gets, the smaller the, buckling stress gets, which means it'll buckle at a smaller load, so...you know, that's the...formula.

Montfort: Okay.

Rita: The explanation for, the longer, the bigger $\mathrm{L}$ the easier it'll buckle. Uhmm

Montfort: Outside of the formula you know that length makes it more susceptible to buckle from lifeexperience, or just remembering homework that you've done, or

Rita: It makes sense, and...you see it all the time.

It is important to note that Rita did not display any more conceptual understanding of this topic than Hank or Lena, but she was much more confident in her ability to answer the questions. Where Hank and Lena were silent or laughed when asked to describe the reasons for their beliefs, Rita displayed very high confidence in ignoring the framework of the specific question and stating, "you see it all the time." 


\section{B. Do engineering students possess as low conceptual understanding of bending as would be assumed from theory and concept inventory results in other fields?}

Table 5 below displays the number of students from each course with a correct ranking for each question. If a student's ranking matched the professors' it was considered a correct ranking, regardless of reasoning. Because Question 2 was not a ranking task, it was not included in this table.

\begin{tabular}{|c|c|c|c|c|c|c|c|c|}
\hline Course & $\mathbf{Q 1}$ & $\overline{Q 3}$ & $\overline{Q 4}$ & Q5 & Q6 & Q7 & Q8 & Number of Interviews \\
\hline $\mathrm{MoM}_{2}$ & $0 \%$ & $0 \%$ & $0 \%$ & $0 \%$ & $25 \%(1)$ & $0 \%$ & $0 \%$ & 4 \\
\hline Struct $_{3}$ & $71 \%(5)$ & $14 \%(1)$ & $0 \%$ & $57 \%(4)$ & $57 \%(4)$ & $28 \%(2)$ & $0 \%$ & 7 \\
\hline Steel $_{4}$ & $67 \%(4)$ & $0 \%$ & $0 \%$ & $33 \%(2)$ & $17 \%(1)$ & $33 \%(2)$ & $0 \%$ & 6 \\
\hline Adv-Steel 5 & $100 \%(4)$ & $0 \%$ & $50 \%(2)$ & $75 \%(3)$ & $100 \%(4)$ & $50 \%(2)$ & $25 \%(1)$ & 4 \\
\hline Average & $62 \%(13)$ & $5 \%(1)$ & $10 \%(2)$ & $43 \%(9)$ & $48 \%(10)$ & $29 \%(6)$ & $5 \%(1)$ & 21 \\
\hline
\end{tabular}

This data supports the general trends discussed above in the following ways: 1) the only significant overall differences in performance were between the $\mathrm{MoM}_{2}$ students and the $\mathrm{Adv}$-Steel $l_{5}$ students; 2) the Steel $_{4}$ students' performance was worse than the Struct 3 students'; and 3) in general, students did not perform well. This data, however, is not sufficient to draw conclusions about the students' conceptual understanding. Tables 6 and 7 refer to students' conceptual understanding.

In Table 6, the underlying concepts for each question are summarized. The concepts listed in Table 6 are not intended to be a complete listing of all the conceptual components of the questions. Table 6 lists the core concepts in each problem situation that were emphasized by this investigation during the design, implementation and analysis of the interviews.

Table 7 provides a summary of student conceptual understanding of each question. In this table the term "standard" will refer to student statements that match the standard understanding of the phenomena used by experts in the field, and "alternative" will refer to any student statements that indicate a different understanding. Recall from conceptual change theory [10] that alternative student beliefs are believed to be the primary barrier to developing conceptual understanding. 


\begin{tabular}{|c|c|c|}
\hline Question & Central Concept & Key Component Concepts \\
\hline Q1 & Stress & $\begin{array}{l}\text { The difference between normal and shear stress, stress distributions in a material due to point and distributed } \\
\qquad \text { loads }\end{array}$ \\
\hline Q2 & Stress & How loadings create stresses, stress concentrations and distributions, definition of stress \\
\hline Q3 & Buckling & $\begin{array}{l}\text { Necessary simplifying assumptions to apply Euler's Buckling equation, the effects and relative importance } \\
\text { of cross-section dimensions and member length in buckling }\end{array}$ \\
\hline Q4 & Buckling & $\begin{array}{l}\text { Necessary simplifying assumptions to apply Euler's Buckling equation, the effects and relative importance } \\
\text { of modulus of elasticity and end condition fixity in buckling }\end{array}$ \\
\hline Q5 & Bending & Relationship between loading and normal stress due to bending \\
\hline Q6 & Bending & Relationship between location on member and normal stress due to bending \\
\hline Q7 & Bending & Relationship between cross-section geometry and normal stresses due to bending \\
\hline Q8 & $\begin{array}{l}\text { Local Buckling } \\
\text { due to Bending }\end{array}$ & Combination of all buckling and bending concepts from Q1 to Q7 \\
\hline
\end{tabular}

Table 6. Overall and component concepts investigated in student responses to each question.

Effectively, alternative beliefs about course content are incorrect. The overall characterization of student conceptual understanding of each question was generated by comparing the number of standard and alternative student quotes, and by analyzing the quality of alternative understandings, including their persistence and deviation from standard. For example, if students had more statements indicating alternative understandings than standard ones, but almost all of the quotes concerned peripheral concepts and many were contradicted within the interviews, student conceptual understanding of that question would still be characterized as "medium." Table 7 is intended to give an introductory overview of the analysis: most meaningful interpretations of this data must depend on more qualitative analysis of student quotes.

\begin{tabular}{cccc}
\hline Question & $\begin{array}{c}\text { Quotations of Alternative } \\
\text { Understandings }\end{array}$ & Quotations of Standard & Overall Characterization of Student \\
\hline Q1 & 27 & Understandings & Conceptual Understanding \\
Q2 & 83 & 42 & Medium \\
Q3 & 75 & 39 & Low \\
Q4 & 71 & 14 & Low \\
Q5 & 111 & 29 & Low \\
Q6 & 62 & 52 & Low \\
Q7 & 78 & 38 & Low \\
Q8 & 72 & 17 & Low \\
\hline
\end{tabular}

Table 7. Number of student statements indicating standard and alternative understandings of each question, and a general characterization of their conceptual understanding of each question. 
Twenty of the 21 students interviewed displayed either significant conceptual difficulties with the concept of bending, or a persistent dependence on equations and memorized processes they could not fully explain. As mentioned above, a preliminary stage of analysis involved scoring each student's response to each question. While this analysis is obviously not a valid quantitative measure of student performance, it revealed that, on average, students displayed an understanding of approximately a third of the fundamental concepts of bending and buckling. This is very similar to the results from the initial, wide-spread implementations of the FCI $[2,26]$. It should be noted that these concepts are truly fundamental, for example the concept that bending is associated with moments.

Figure 3 below shows the instructions and figures presented to students for Question 2. This question was not a ranking task, but asked students to "describe the stresses that would develop at the points of interest in the two figures." Further questions asked students to describe how they would calculate those stresses, what caused the stresses and "if you knew these stresses, what could you predict about the members' behavior?"
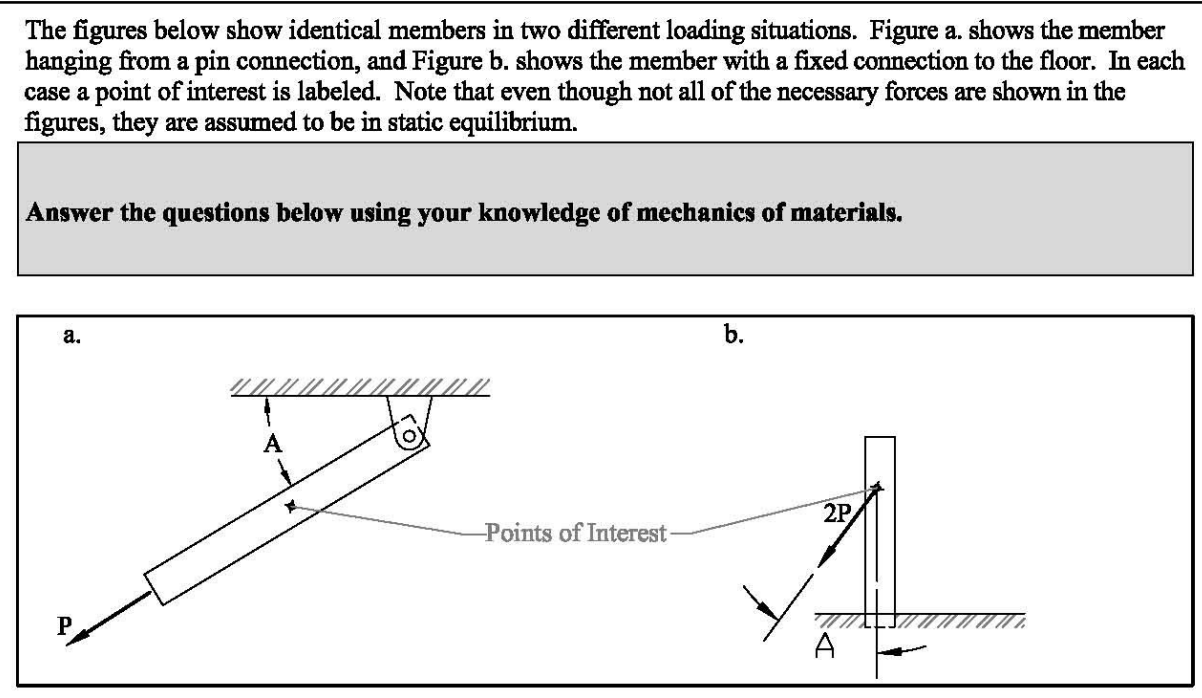

Figure 3. Figures and instructions used for Question 2.

Describing and calculating stresses to analyze member behavior is the central purpose of mechanics of materials. These skills would be taught in every mechanics of materials course, and used frequently throughout the curriculum of other structures courses. However, 13 of the 21 students (including 2 of the 4 graduate students) did not display conceptual understanding when interviewed. For example Pete, a Steel ${ }_{4}$ student described the stresses present in figure b of Question 2 (shown above in Figure 3) in the following way:

Pete: ...Uhmmm. Tensile and compression. 
Montfort: Tensile and compression?

Pete: Yeah, and uh...well...it's causing, it's gonna cause a moment too. So that'd be a, some, tor, is that torsion?

Montfort: Yeah.

Pete: [laughing] I don't know

Montfort: There is a stress called torsion, yeah. What makes you, what makes you say torsion?

Pete: Well, it uh, there's a...you got a fixed connection here. Is that?

Montfort: mm-hmm.

Pete: Yeah, fixed. It's uh...that force there is gonna, wanna. Well, torsion's twisting so

Montfort: yeah.

Pete: What am...I'm trying to

Montfort: In terms of stresses what would you say?

Pete: Compression. Uhm. And shear. I don’t know!

Andy, an $A d v$-Steel ${ }_{5}$ student knew that it was common to break a force like the one shown in figure $\mathrm{b}$ of Question 2 into components, but he seemed to believe that this was based on the physical properties of stress rather than computation convenience. He reasoned,

Andy: Obviously you have a cross-section....at...each point will be the same. But. The force is what's gonna be different. Uhm. It. Oh shoot. So on this one you're gonna have...you're gonna have a component of the force...you know like over, like one area, so like...the part that's pulling down would act over like....an area and then...the force pulling out would act over a different area?

\section{Which aspects of students' conceptual understanding (beliefs) of bending phenomena change as students progress through their undergraduate and Master's level courses?}

As discussed above, students' conceptual understanding varied from student to student, but generally not from course to course. Although the $A d v-$ Steel $_{5}$ students were usually more able to recall and apply pertinent equations, this use of equations usually masked underlying confusion that was more obvious in other students' comments. For example, all of the graduate students recalled Euler's Buckling formula in Question 3 (shown above in Figure 2). 
Question 3, shown below in Figure 4 required the students to interpret that formula to determine which properties were more important in buckling. Luke, an $A d v-$ Steel $_{5}$ took 10 minutes to calculate equivalent strength values for each of the figures, and was completely confident that this approach gave him the correct answer. However, because he didn't address the assumptions he was making by using particular equations, his rankings were confused. A revealing line of reasoning occurs when Luke is asked to explain one of his calculated values: he said that b would be "one-fourth" as strong as e.

Montfort: Why do you know it's less than a fourth?

Luke: Uhm. Because it's the one fourth. Cubed?

Montfort: mm-hm.

Luke: Does that make sense? So one fourth cubed is less than a fourth

Montfort: less than a fourth.

Luke: Yeah. That's because the $\mathrm{H}$ is cubed, so, if that, if that makes sense.

Montfort: Yeah.

Luke: So the other one, the weakest one after that was that, so it's gonna be weaker than this guy. Montfort: Okay.

Luke: Which...makes sense if you just think about, even, even without numbers cuz it's....the only difference, well the length is, is also there. Sooo, I guess that might make sense, but yeah, it should be less than a fourth. Would be my bet.

Like most of the sophomores, juniors and seniors interviewed, Luke is unable to conceptually understand how the geometry of a column relates to buckling but this lack of understanding is hidden beneath math skills and familiarity with the equations. Luke's intuition seems to contradict his calculations (“...I guess that might make sense...”), but is immediately overridden by his confidence in the numbers (“...it should be less than a fourth”). 
The figures below represent six different columns. The columns have different end conditions: either fixed at the bottom and free at the top, pinned at the bottom with rollers at the top, or fixed at the top and bottom. The modulus of elasticity (E) of each column also varies. The columns all have the same geometry, and are subjected to the same load $\mathbf{P}$.

Rank these columns in the order they would buckle in (from least to most resistant to buckling) if $P$ were gradually increased. It may not be possible to distinguish between all of the figures, so more than one figure can have the same ranking.
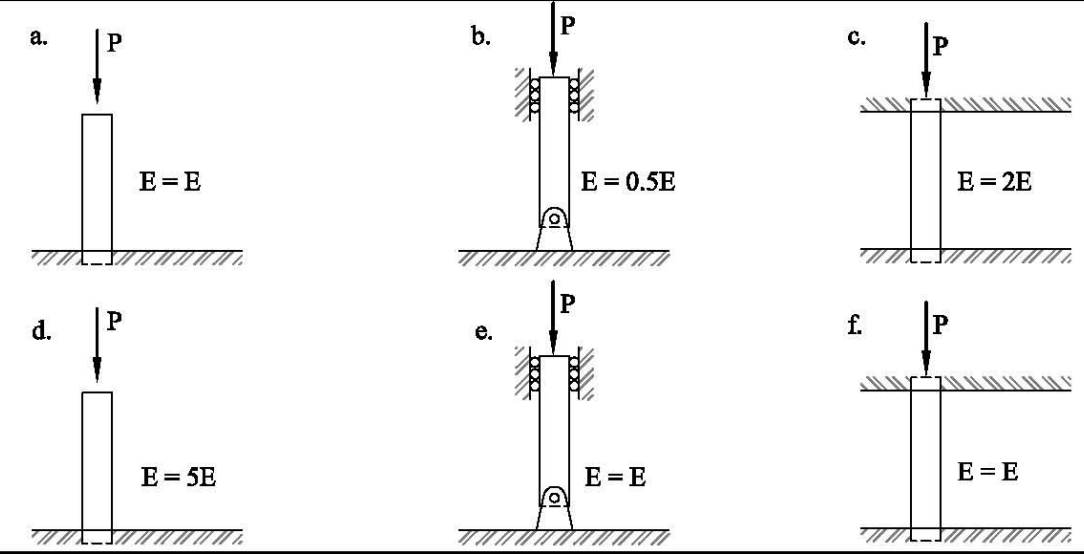

Figure 4. Instructions and figures from the ranking task used in Question 3.

\section{Which beliefs are resistant to change in light of counter evidence presented in their courses?}

Students at all levels had difficulty relating loading to stress distributions. This difficulty took several forms during the interviews. Question 1, shown below in Figure 5, elicited the most striking student statements about this confusion because of its simplicity.

In their responses to Question 1 many students were confused about how a point load and a distributed load would cause different stresses. Some students believed that distributed loads cause more stress than point loads. For example, a Steel 4 student reasoned "I would definitely do...4P first. Because number one it's $4 \mathrm{P}$ and it's a distributed load?... Uhm...then I'd probably do this one because it's still a distributed load, even though it's point 5 P?" A different Steel $_{4}$ student believed the opposite, stating "I don't know how it [the distributed load] compares to the single P's, but...I would think it's still gonna be less than all of them." Several students relied entirely on a mathematical expression of stress, and were unable to use the definition in their reasoning. For example, one $M o M_{2}$ student reasoned "Because if it's, uhm, if the area of this was, say like a tenth of a meter or something, and this is uh, the force was, like kilonewtons per meter, it would be less than the actual force." 
The figures below show identical cubes with all sides of length $X$. Each cube is subjected to a different loading, represented by the arrows in the figures. Note that even though not all of the necessary forces are shown, the cubes are assumed to be in static equilibrium.

Rank these figures according to the vertical stresses on a plane passing horizontally through the center of the cube (shown as a shaded square), from highest stress to lowest. It may not be possible to distinguish between all of the figures, so some figures may have the same ranking.

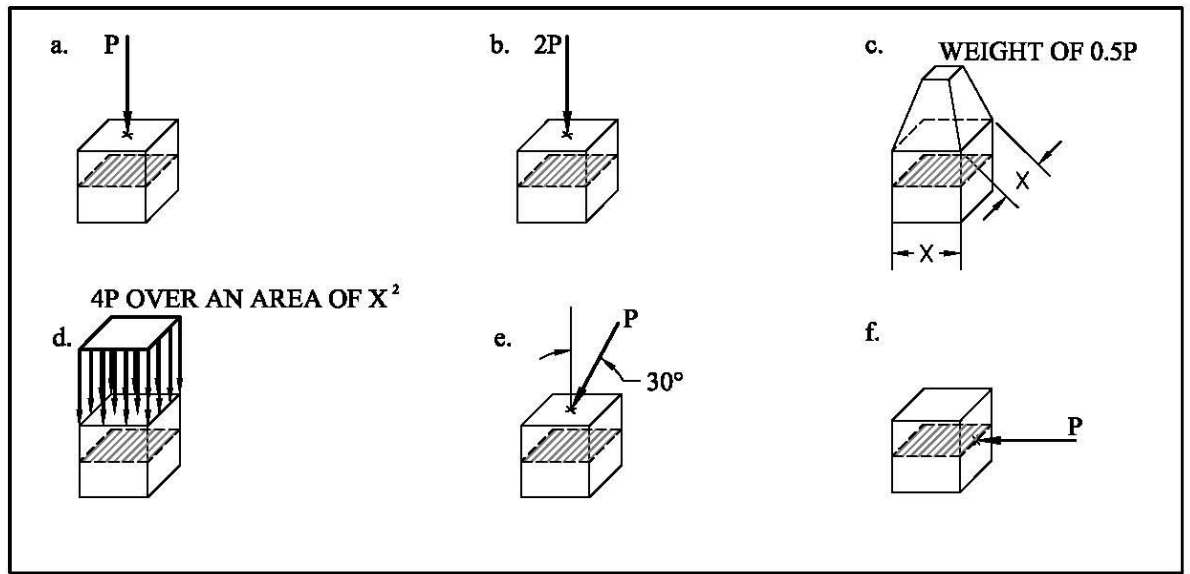

Figure 5. Instructions and figures from the ranking task used in Question 1.

In response to Question 2 (shown above in Figure 3), approximately half the students were unable to identify all of the stresses that would develop as a result of the simple loadings shown. The confusion seemed primarily caused by uncertainty about bending. Question 5, shown below in Figure 6, required students to compare normal stresses due to bending in identical beams under different loadings. Although most students—even those were unable to describe the bending in Question 2-correctly stated that normal stresses in bending are due to moment, they were still unable to determine how distributed loads would affect normal stresses. Many students from all the courses condensed the distributed loads into an equivalent point load, which indicates that their understanding of how moment causes normal stresses does not include how the normal stresses are distributed through the beam. For a point load, as shown in Figure 1 above, the value of the internal moment varies linearly because only the distance from the load and reactions is changing. When a distributed load is applied to a beam, the value of the internal moment changes parabolically along the beam because both the distance and the value of the load are changing, and the internal moment at any point is equal to the distance from the load times the value of the load. 
The figures below show identical members of length $L$ and width $W$, with identical sections. Each is supported by a pin on the left, and a roller on the right. Each is loaded differently as represented by the arrows in the figures.

Rank these figures according to the normal stresses developed due to bending at the point indicated, from highest stress to lowest. It may not be possible to distinguish between all of the figures, so some figures may have the same ranking.

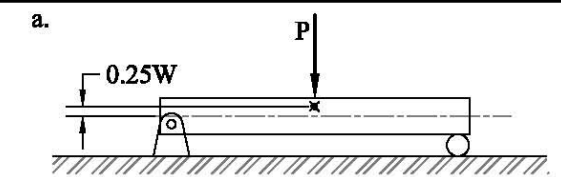

c.

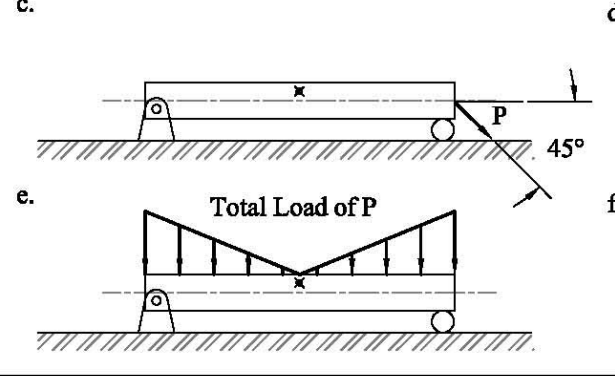

b.

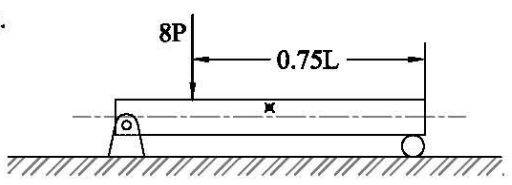

d.

$\mathrm{P} / \mathrm{L}$

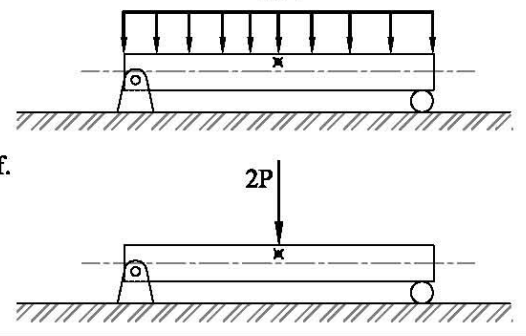

Figure 6. Instructions and figures from the ranking task used in Question 5.

Students seemed at least superficially aware of this difficulty. Most students either drew or mentioned the vertical distribution of normal stresses in response to Question 5 even though the point under consideration (shown as a small " $\mathrm{X}$ " in Figure 6 above) did not move. The vertical distribution did not help any students with their analysis, but it was a frequent response their difficulties in relating load to stress. For example, when asked what causes the normal stresses in Question 5, Pete, a Steel $_{4}$ student, timidly guessed "The position of the load?" This answer could be correct if it was supported with an understanding of how load position affects the bending moment, and how the bending moment affects the normal stresses. Pete's supportive reasoning, however, is interestingly unrelated. He said,

Pete: Uhm, lessee, so if. If it was at the center of the beam here

Montfort: $\mathrm{mm}-\mathrm{hmm}$.

Pete: I would say that it would be zero.

Montfort: Okay.

Pete: Uhm. Since it's closer to the top it'd be, uh, compression.

Montfort: Okay. 
Pete: Uhm. Since it's going down, and at the bottom, it'd be uh, tensile, uhm. In the member.

Montfort: mm-hmm.

Pete: I mean is that, is that what you're wanting?

Pete is unable to determine what causes the normal stresses in bending, but he somehow knows that this lack of knowledge is related to his lack of understanding of how those stresses are distributed through the beam. Rod, a Struct $_{3}$ student, also makes a series of statements that reveal he knows what he should understand, but still cannot make sense of it. When asked, "If you just saw this set-up in a homework problem, and you hadn't read the description yet, what would you expect the problem to be about? What does that mean to you, that picture," Rod responds first with what he knows. He says,

Rod: Uh, I would say...[pause] Hm. Probably they're gonna ask you to...well, okay. It's gonna bend, like this? Obviously, and then, uhm, so then the top part will be in compression. So, this part is...h, like halfway in the top part, so. I mean, this little member is gonna be in compression, but, it's also gonna be in compression this way because the force is directly above it?

At this point, even though the interviewer says "Okay," Rod realizes he has not answered the question and says "So, I don't know, they're probably asking you to find [pause] like what the s, I don't know, I guess what the stress is, on that one...member, in both directions or something? Yeah, sorry, I don't know."

\section{E. Which of these beliefs can be considered misconceptions?}

It appears that students had trouble relating loading to stress because of how they visualized point loads affecting the members. Many students, and all of the students who had consistent difficulty relating loading to stress, used reasoning that depicted stress as a liquid that seeped through the member, spreading out from the point of contact with the load. Figure 7 below displays a possible representation of this belief. 


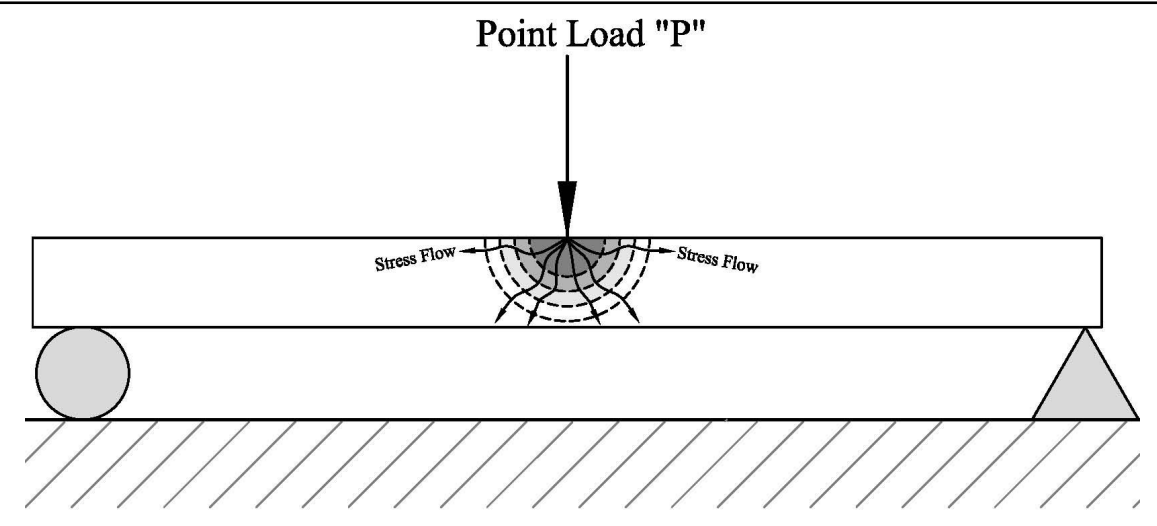

Figure 7. Representation of the misconception that stress flows out from loadings in beams.

This belief can be considered a misconception because it interferes with a correct understanding of many topics and because it persists even when students possess directly contradictory knowledge [10]. Rod's prediction of what types of questions would typically be asked about the situation presented in Question 5 (see Figure 6 above) is an excellent example of this. In the same statement Rod demonstrates that he is aware of the vertical distribution of stresses in a beam (“...so then the top part will be in compression”), and that he believes the parts of the beam underneath the load will experience stress in the direction of the load ("but, it's also gonna be in compression this way because the force is directly above it").

This misconception is most apparent in student responses to Questions 6,7 and 8. In response to Question 6 (shown below in Figure 8), approximately half of the students interviewed (11 of 21) reasoned like Andy, an AdvSteel $_{5}$ student who said “...so since that's farther away, there's actually gonna be less stresses, cuz you know, as you get farther away from the load, you know, the stress would be less so I'm gonna say that. Mm, most stresses would occur closer to P...." Even though Andy's analysis of the previous question disproved this statement at several points, he remained confident that it was generally true, saying "It's just like, it gets taught in every class, but...it comes...it, and it, I mean you could almost. You don't even have to almost apply it, it just makes more sense.” 
The figures below show identical members of length $\mathrm{L}$, with identical sections, under identical loads. Each is supported by a pin on the left, and a roller on the right.

Rank these figures according to the normal stresses developed due to bending at the point indicated, from highest stress to lowest. It may not be possible to distinguish between all of the figures, so some figures may have the same ranking.

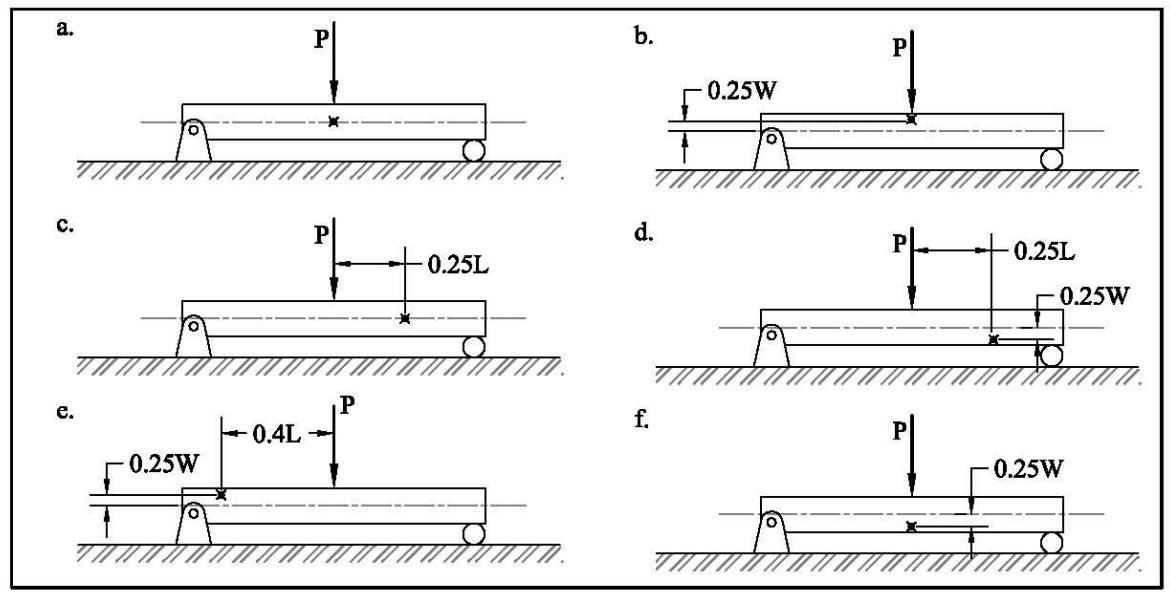

Figure 8. Instructions and figures from the ranking task used in Question 6.

Andy and most other students were able to correctly identify moment as the cause of normal stresses in bending and to at least partially apply this concept to Question 5. When asked in Question 6 to compare different points on a bending beam under the same loading, however, students' reasoning was impaired by the misconception that stress flows out from a point load.

In response to Questions 7 and 8 (shown on the following page in Figures 9 and 10, respectively), this misconception led many students to ignore their previous statements about bending, and instead focus on the idea of the web supporting the vertical bending load. For example, Brian, a Struct ${ }_{3}$ student compared two figures by stating, “these two are quite similar except this one's got another part, so that extra part can hold more force, can just help distribute the force more." Brian was one of the many students to accurately draw the vertical distribution of normal stresses in response to Question 5. The knowledge that he displayed when trying to rank the figures in Question 4 contradicts the belief that the web "supports" the bending load, but Brian's belief persists due his stress flow misconception. Barb, a Steel 4 student, stated, “...and these are gonna buckle first, but then this is gonna be transmitted through this web? Which could make that one...less susceptible to buckle, so, I'll say that. Because there's gonna be more transmitted, like, through the thicker web, you know what I mean?" 
When asked to rank the normal stress developed in different cross-sections in Question 7 (see Figure 9 below), many students displayed a similar belief that stress flows outward from a load. Lena was very reluctant to speak when presented this question, and said "Mmm-hm. Uhm [long pause] It's not supported.... [Montfort says 'Okay'] In the middle," when asked why figure e is more susceptible to bending than figure f. Similarly Heidi, a $\mathrm{MoM}_{2}$ student was asked "what do you think is important about, the section," and responded "Uhm. Well I think that maybe, this one probably has the least, because it seems to be, more supported." Using the idea of a "supportive" cross-section is an indicative of this misconception because a) it is incorrect because it is a section's moment of inertia about the neutral axis that affects the normal stress developed from bending; 2) it is indicative of a deep misunderstanding of the concepts of bending and moment because they both depend on horizontal distance from the load, and; 3) it coexists and interferes with correct beliefs. Heidi and Lena displayed that they knew that moment would be used to calculate normal stresses in their responses to Question 5 (see Figure 6 above), but were unable to reconcile this fact with their belief that the stresses flowed out from the load.

This is consistent with the theory of misconceptions $[10,34]$ because more of the students were not familiar with phenomenon of local buckling. The students were constructing their knowledge as they responded, and had less surface-level knowledge to guide them.

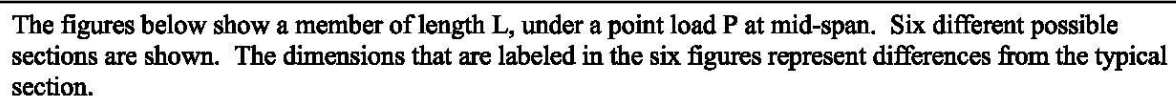

Rank these figures according to the normal stress developed due to bending at the point indicated, from highest to lowest. It may not be possible to distinguish between all of the figures, so some figures may have the same ranking.

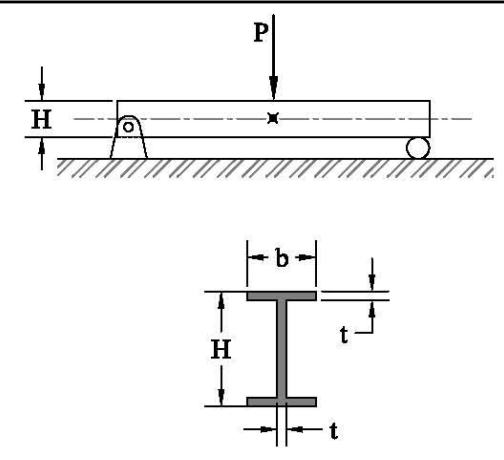

TYPICAL SECTION

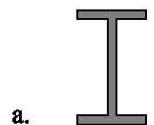

d.

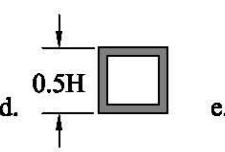

b.
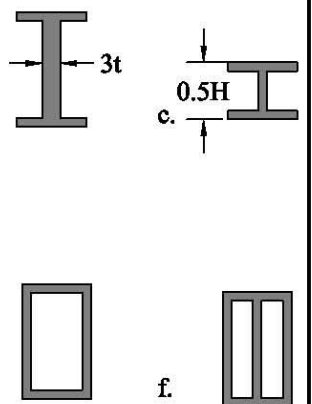

f. 
Figure 9. Instructions and figures from the ranking task used in Question 7. Note that the point indicated is on the neutral axis, so there would be no normal stresses. A point $0.25 \mathrm{H}$ above the neutral axis was marked and described by the interviewer during each interview. The figures below show a member of length $\mathrm{L}$, under a distributed load of magnitude $\mathrm{P}$ along its entire length.
It is supported by a pin on the left, and two rollers on the right. Six different possible sections are shown.

The dimensions that are labeled in the six figures represent differences from the typical section.

Rank these figures according to their susceptibility to local buckling in the flange, from highest to lowest. It may not be possible to distinguish between all of the figures, so some figures may have the same ranking.

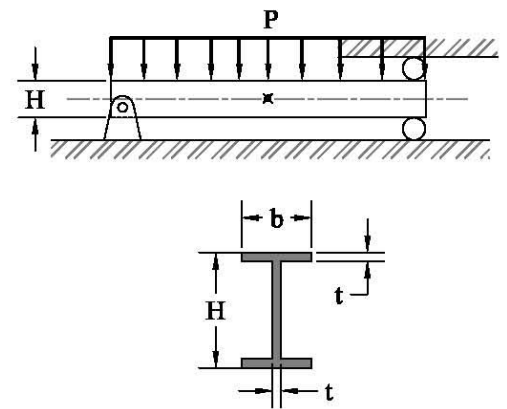

TYPICAL SECTION

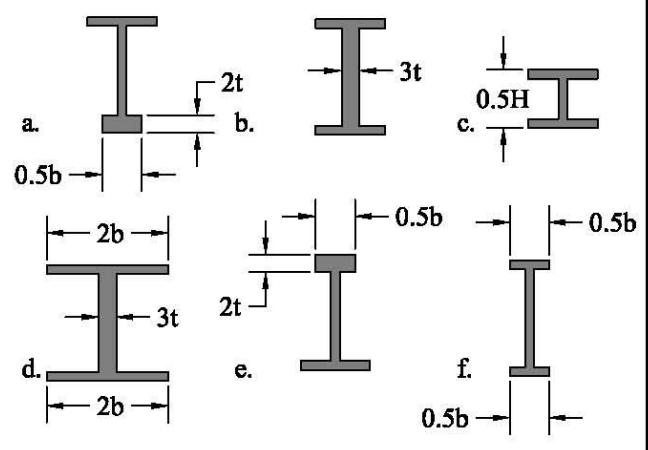

Figure 10. Instructions and figures from the ranking task used in Question 8. Students were asked to ignore the small " $X$ " indicating a point in this figure because local buckling can not be considered for a point.

Students' difficulty with the concept of stress, and in particular, their tendency to describe it as a physical substance matches trends other researchers have identified in thermodynamics, physics and electrical engineering [35-37]. Stress is similar to force, voltage, diffusion and heat because they all cause robust misconceptions. Chi theorizes that this is because these concepts are a new type of object—which she calls an "emergent process" [35]— and developing conceptual understanding of these concepts requires not just new knowledge, but new ontological skills [38].

\section{F. Can students carry fundamental misconceptions with them through their engineering academic careers and still be successful?}

The results of this study indicated that student misconceptions of normal stress in bending do not change significantly over the course of the engineering academic careers. It appears that students undergo conceptual change most markedly during their senior year, but that not all fundamental misconceptions are addressed. It is worth reiterating that all of these students were chosen by their instructors as among the "best" students in their 
respective classes. These students have achieved remarkable academic success in their structural engineering courses-in two cases a perfect 4.0 grade-point average-without developing a comprehensive understanding of bending stress and buckling.

\section{Discussion of counter-explanations}

The following issues will be addressed in this sub-section: 1) the possible disconnect between content emphasized in class and content evaluated in this study; 2) the possibility of misrepresenting the student population due to a small sample size and, 3) the possibility that students' discomfort during the interviews interfered with the expression of their true level of understanding.

The structural steel design courses at WSU now emphasize the concept of "capacity" instead of stress. This shift is part of a larger change in structural engineering practice to a new design paradigm: Load and Resistance Factor Design (LRFD). In the older Allowable Stress Design (ASD) method, design calculations were based on the magnitude of stress a member could withstand. This is a material-centered perspective, but most structural engineering problems are more concerned with loads: e.g. what combined loads from wind and snow loads should a roof system be able to safely support. LRFD and ASD designs currently operate at the level of loads. When analyzing bending the shear forces and moments are calculated and then compared to standardized, factored shear and moment capacities.

This means that students do not gain sustained experience with the concept of stress after $M o M_{2}$. It is arguable then that seniors' and graduate-students' understandings of stress may not be considerably different than sophomores', and could even be less due to their distance from the material. While not weakening the conclusions stated in this study, this fact would decrease their significance.

It is debatable, however, that capacity and stress are truly distinct concepts. Because stress causes failure and capacity is a concept that is dependent on the concept of failure, stress is integral part of the concept of capacity. The relationship between concepts is one of the main features of constructivist learning [15] and the definition of conceptual understanding adopted by this study. Also, the emphasis on capacity instead of stress does not explain the trends of student understanding between courses.

In interviews with 21 students, 17 of which were currently in courses emphasizing capacity over stress, six students said the word "capacity." For four students the word was used in the middle of a successful stress-based analysis, indicating that they did not separate the two concepts but that this did not interfere with their reasoning. 
The two other students (interestingly, both students in Steel $_{4}$ ), seemed confused by their attempted application of the concept to the interview questions. For the students who expressed an awareness of it, the concept of capacity was not clearly distinguishable from stress, indicating low conceptual understanding of both concepts.

It is possible that the results reported above do not reveal much about the engineering student population because they are based on data from too small a sample to be representative. This particular concern is addressed above in the Sample Selection sub-section of the Methods. It worth noting again, however, that the significance of the results does not depend on the students being representative. It is a significant finding in itself that five senior civil engineering students have difficulty with the concept of stress and are receiving A's in a steel design course.

The most potentially damaging counter-explanation is that the interviews did not accurately reveal the students' understanding because of the unfamiliarity of the situation and their resulting discomfort. This is a definite concern when conducting any interviews, and was addressed in this study by encouraging an atmosphere of curiosity and sharing during the interviews. Each interviewee expressed some discomfort in describing their reasoning at first, but quickly became more talkative as they were encouraged.

\section{CONCLUSION}

The students interviewed, with very few exceptions, seemed to use the same approach to problem-solving. At the beginning of the interview each student was told that the purpose of the research was to study how students understand mechanics of materials conceptually. However, each student seemed to approach the problem as if problem-solving were a simple if-then logical statement: if it is a problem of type A, we use equation B. Most of the students interviewed were confident in their classifications of the types of problems, but linking those categories to equations seemed to correlate to academic year. The uniformity of approach suggests that this approach is linked with academic success.

These inferences obviously require more direct research to be supported, but they imply an underlying cause of the persistence of low conceptual understanding among STEM students. Whether students who prefer the problemcategorization approach are naturally more successful, or success relates to how well students learn that approach does not matter as much as how this approach is selected for in the academic program. It is a highly methodical approach that requires skill, but it is antithetical to conceptual understanding. Additionally, the skills students develop to quickly categorize text-book problems and recall a theoretical equation will not serve them as practicing 
engineers where they will be faced with a bewildering variety of problems, and be required to move beyond clean, memorizeable formulas.

The conceptual discomfort displayed by the students in the $\mathrm{Steel}_{4}$ course suggests that they are undergoing conceptual change. Steel $_{4}$ is a senior-level course because of the specificity of its content and the emphasis on design problems. The reasoning is that students who had not first learned the fundamentals would not be interested or successful in the course. The results of this study support this reasoning by showing that the students in that course are being forced to examine their conceptual understanding of fundamental mechanics of materials, and that students in graduate courses are more confident. However, the students in $A d v-S t e e l_{5}$ possessed the same misconceptions as students in $\mathrm{MoM}_{2}$; this suggests that although the conceptual change is initiated in $\mathrm{Steel}_{4}$, it is not necessary to succeed in the course, and is not being completed. If future research observes the phenomena of design-inspired conceptual change, the next step will be to identify specific aspects of these design courses that cause conceptual change. Although this research should be guided by theory, it will likely need to begin as an exploratory qualitative analysis involving student and faculty opinions. After the theoretical framework and exploration have narrowed the list of factors to be considered, more specific analyses should be performed.

Further research will need to be performed to confirm the generalizeability of the characterization of student understanding made in this study. Specifically, future research could focus on the following questions: do students who are academically less successful possess different misconceptions than academically successful students; do similar patterns in student conceptual understanding exist in concepts that are categorized as "easy" by professors; would students exhibit richer conceptual understanding if the interviews had been phrased in terms more similar to the day-to-day content of their current classes, i.e. in terms of capacity instead of stress; and do students at similar universities exhibit similar conceptual understandings and what characteristics of a university affect student conceptual understanding of these topics?

In the context of engineering education research it is not surprising that academically successful students do not possess robust conceptual understanding of fundamental concepts in their field. This finding is not an indictment of those students, their instructors or the collegiate education system; the purpose is not to reveal someone's failure, but to describe a problem facing stakeholders in engineering education. The primary purpose of investigating and describing students' misconceptions in mechanics of materials is to serve as a basis for future research which will address those misconceptions. 
Because addressing students' low conceptual understanding requires systemic changes, people at all levels of engineering education must first be convinced that it is a problem. Further work with the specific misconceptions identified in this study could include the development of a survey to assess student conceptual understanding of normal stresses due to bending. A broadly-implemented survey would produce quantitative, easily interpreted data that could be efficiently shared with many engineering educators. 


\section{REFERENCES}

Steif, P.S., A. Dollar, and J. Dantzler, Results from a Statics Concept Inventory and their Relationship to other Measures of Performance in Statics, in Frontiers in Education. 2005: Indianapolis, IN.

Hake, R.R., "Interactive-engagement versus traditional methods: A six-thousand-student survey of mechanics test data for introductory physics courses", American Journal of Physics, 1998, 66 No. 1, p. 64-74

Evans, D.L., et al. Progress on Concept Inventory Assessment Tools. in Fronteirs in Education. 2003. Boulder, CO.

Halloun, I.A. and D. Hestenes, "The initial knowledge state of college physics students", American Journal of Physics, 1985, 53 No. 11, p. $1043-1048$

Richardson, J., J. Morgan, and D. Evans, Development of an Engineering Strength of Material Concept Inventory Assessment Instrument, in ASEE/IEEE Frontiers in Education Conference. 2001: Reno, NV.

Olds, B.M., R. Streveler, and M.A. Nelson, Preliminary Results from the Development of a Concept Inventory in Thermal and Transport Science, in ASEE Annual Conference and Exposition. 2004.

Trowbridge, D.E. and L.C. McDermott, "Investigation of student understanding of the concept of velocity in one dimension", American Journal of Physics, 1980, 48 No. 12, p. 1020-1028

Piaget, J., The Origins of Intelligence in Children. the Norton Library. 1963, New York: International Universities.

Limón, M. and L. Mason, Reconsidering Conceptual Change: Issues in Theory and Practice. 2002, Boston: Kluwer Academic.

Chi, M.T.H. and R.D. Roscoe, The Processes and Challenges of Conceptual Change, in Reconsidering Conceptual Change: Issues in Theory and Practice, M. Limón and L. Mason, Editors. 2002, Kluwer Academic Publishers: Boston.

Lawson, R.A. and L.C. McDermott, "Student understanding of the work-energy and impulse-momentum theorems", American Journal of Physics, 1986, 55 No. 9, p. 811-817

Kautz, C.H., et al., "Student understanding of the ideal gas law, Part II: A microscopic perspective", American Journal of Physics, 2005, 73 No. 11, p. 1064-1071

Kautz, C.H., et al., "Student Understanding of the Ideal Gas Law, Part I: A macroscopic perspective", American Journal of Physics, 2005, 73 No. 11 , p. 1055-1063

McDermott, L.C., Physics by Inquiry. Vol. I \& II. 1996, New York: John Wiley \& Sons, Inc.

Bruner, J.S., The Process of Education. 1960, Boston: Vintage Books.

Bransford, How People Learn: Brain, Mind, Experience and School, ed. N.R. Council. 2000, Washington: National Academy Press.

Lising, L. and A. Elby, "The impact of epistemology on learning: A case study from introductory physics", American Journal of Physics, 2005, 73 No. 4, p. 372-382

Prince, M.J. and R.M. Felder, "Inductive Teaching and Learning Methods: Definitions, Comparison, and Research Bases", Journal of Engineering Education, 2006 No.

Tobias, S., They're Not Dumb, They're Different: Stalking the Second Tier. 1990, Tuscon, AZ: Research Corporation.

Tobias, S., Revitalizing Undergraduate Science: Why Some Things Work and Most Don't. 1992, Tuscon, Arizona: Research Corporation.

Leydens, J.A., B.M. Moskal, and M.J. Pavelich, "Qualitative Methods Used in the Assessment of Engineering Education", Journal of Engineering Education, 2004, 93 No. 1, p. 65-72

Robson, C., Real World Research: A resource for social scientists and practioner-researchers. 1993, Malden, MA: Blackwell Publishers. 
Patton, M.Q., Qualitative Research and Evaluation Methods. 3 ed. 2002, Thousand Oaks, Calif: Sage Publications.

Brown, S., D. Montfort, and K. Findley. Student understanding of states of stress in mechanics of materials. in ASEE Annual Conference and Exposition. 2007. Honolulu.

Brown, S., D. Montfort, and K. Findley. Development, implementation, and assessment of a bending stress tutorial. in Frontiers in Education. 2007. Milwaukee, WI.

Hestenes, D., M. Wells, and G. Swackhamer, "Force Concept Inventory", The Physics Teacher, 1992, 30 No., p. 141-158

Ginsburg, H.P., Entering the Child's Mind: The Clinical Interview in Psychological Research and Practice. 1997, New York: Cambridge University Press.

Piaget, J., The Child's Conception of Movement and Speed. 1970: Ballantine.

O'Kuma, T.L., D.P. Maloney, and C.J. Hieggelke, Ranking Tasks in Physics: Student Edition. 2003: Benjamin Cummings. 240.

Vygotsky, L., Thought and Language, ed. E. Hanfmann and G. Vakar. 1962, Boston: MIT Press.

Maykut, P. and R. Morehouse, Beginning qualitative research: A philosophical and practical guide. 1994, Washington DC: Falmer Press.

Atlas t.i. 2007, Scientific Software.

Miles, M.B. and A.M. Huberman, Qualitative Data Analysis. 2nd ed. 1994, Thousand Oaks: Sage.

Mayer, R., Understanding conceptual change: A commentary, in Reconsidering Conceptual Change: Issues in Theory and Practice, M. Limón and L. Mason, Editors. 2002, Kluwer Academic Publishers: Boston.

Chi, M.T.H., "Commonsense Conceptions of Emergent Processes: Why Some Misconceptions Are Robust", The Journal of the Learning Sciences, 2005, 14 No. 2, p. 161-199

Reiner, M., et al., "Naive Physics Reasoning: A Commitment to Substance-Based Conceptions", Cognition and Instruction, 2000, 18 No. 1, p. 1-34

Streveler, R., et al., The Development of a Professional Knowledge Base: The Persistence of Substance-based Schema in Engineering Students, in American Educational Research Association. 2006: San Francisco. p. 1-30.

Slotta, J. and M.T.H. Chi, "Helping Students Understand Challenging Topics in Science Through Ontology Training", Cognition and Instruction, 2006, 24 No. 2, p. 261-289 
ApPendix A 
The figures below show identical cubes with all sides of length $\mathrm{X}$. Each cube is subjected to a different loading, represented by the arrows in the figures. Note that even though not all of the necessary forces are shown, the cubes are assumed to be in static equilibrium.

Rank these figures according to the vertical stresses on a plane passing horizontally through the center of the cube (shown as a shaded square), from highest stress to lowest. It may not be possible to distinguish between all of the figures, so some figures may have the same ranking.

a.
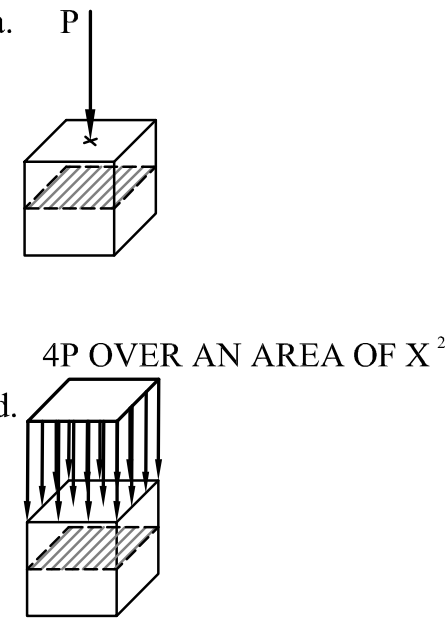

b. $2 \mathrm{P}$

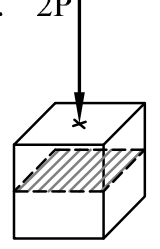

e.

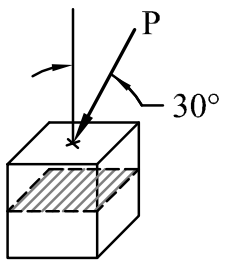

c.

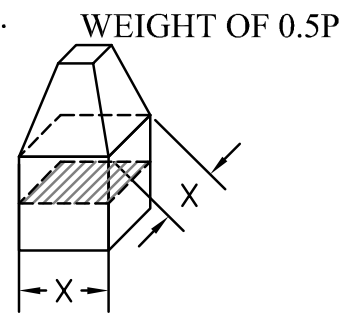

f.

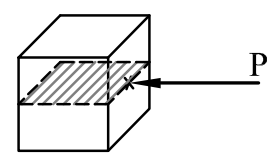

Ranking:
1)
2)
3)
4)
5)
6)

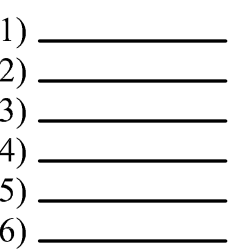

Please describe your reasoning:

What key equations or properties did you use to make your ranking? 
The figures below show identical members in two different loading situations. Figure a. shows the member hanging from a pin connection, and Figure b. shows the member with a fixed connection to the floor. In each case a point of interest is labeled. Note that even though not all of the necessary forces are shown in the figures, they are assumed to be in static equilibrium.

Answer the questions below using your knowledge of mechanics of materials.

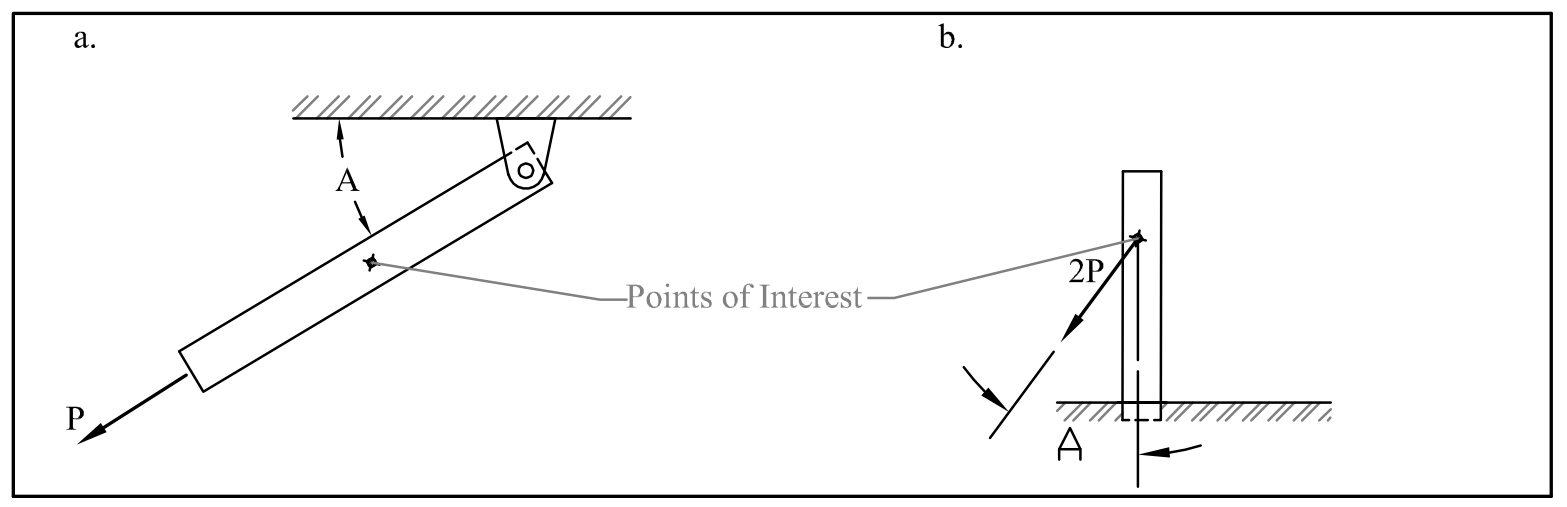

1) Describe the stresses that would develop at the points of interest in the two figures.

2) How would you go about calculating them?

3) What causes these stresses?

4) If you knew these stresses, what could you predict about the member's behavior? 
The figures below represent six different columns. Each column is fixed at the bottom, free at the top and subjected to the load P. The six figures represent a column with the width (W), length (L) and depth (D) listed under the load $\mathrm{P}$.

Rank these columns in the order they would buckle in (from least to most resistant to buckling) if $P$ were gradually increased. It may not be possible to distinguish between all of the figures, so more than one figure can have the same ranking.

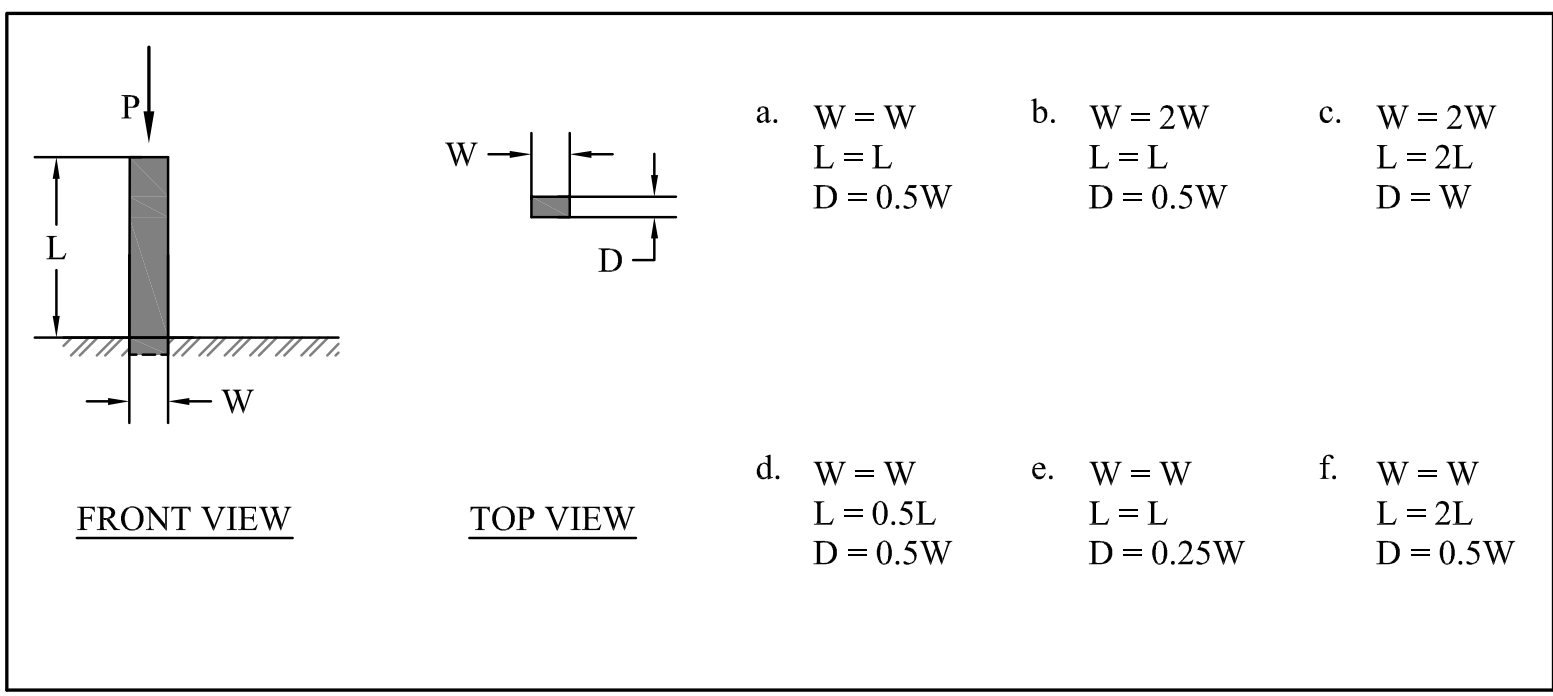

Ranking:

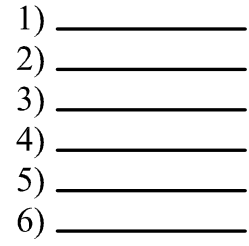

Please describe your reasoning:

What key equations or properties did you use to make your ranking? 
The figures below represent six different columns. The columns have different end conditions: either fixed at the bottom and free at the top, pinned at the bottom with rollers at the top, or fixed at the top and bottom. The modulus of elasticity (E) of each column also varies. The columns all have the same geometry, and are subjected to the same load $P$.

Rank these columns in the order they would buckle in (from least to most resistant to buckling) if $P$ were gradually increased. It may not be possible to distinguish between all of the figures, so more than one figure can have the same ranking.

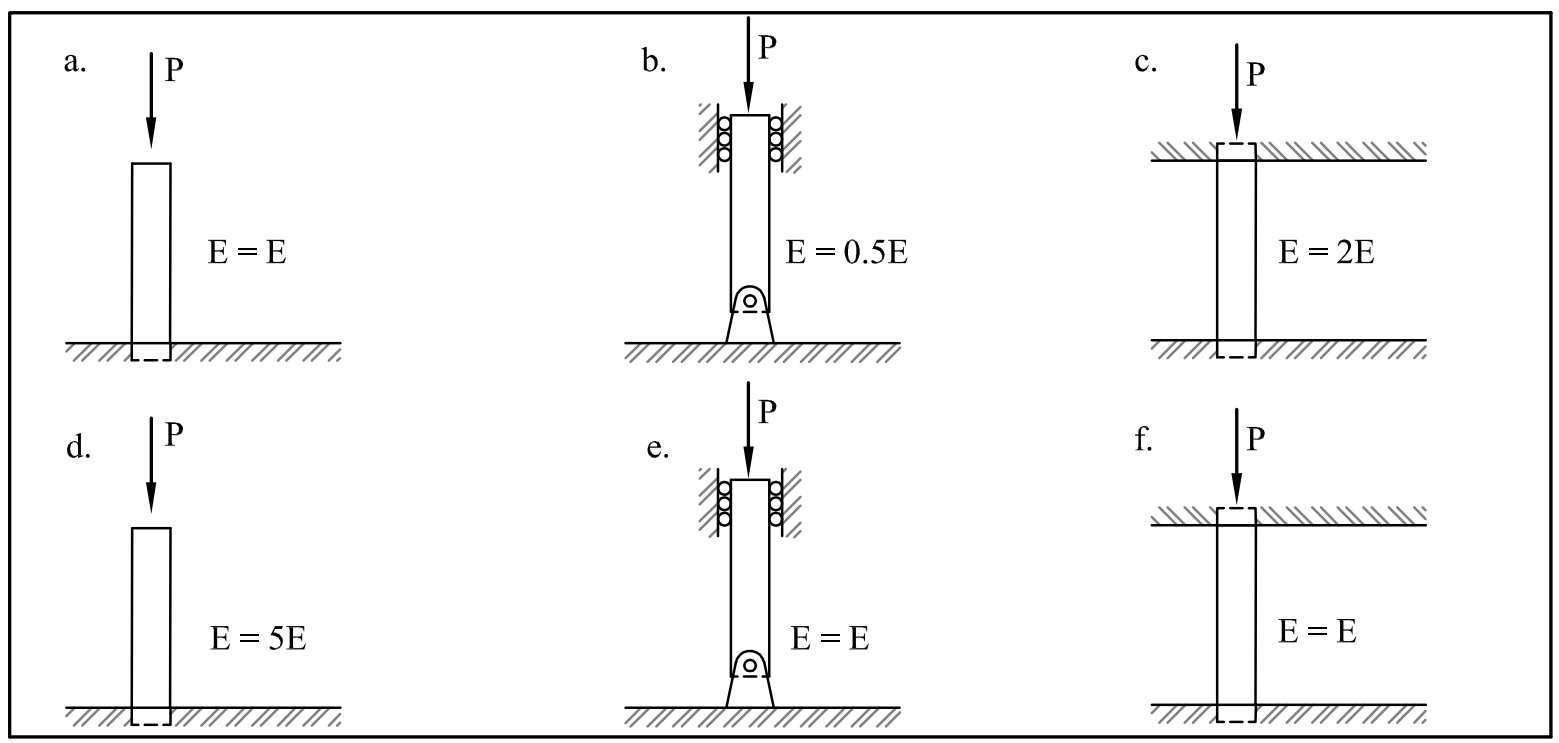

Ranking:

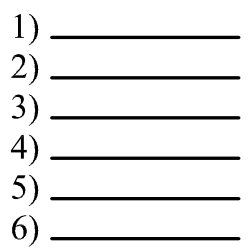

Please describe your reasoning:

What key equations or properties did you use to make your ranking? 
The figures below show identical members of length $\mathrm{L}$ and width $\mathrm{W}$, with identical sections. Each is supported by a pin on the left, and a roller on the right. Each is loaded differently as represented by the arrows in the figures.

Rank these figures according to the normal stresses developed due to bending at the point indicated, from highest stress to lowest. It may not be possible to distinguish between all of the figures, so some figures may have the same ranking.
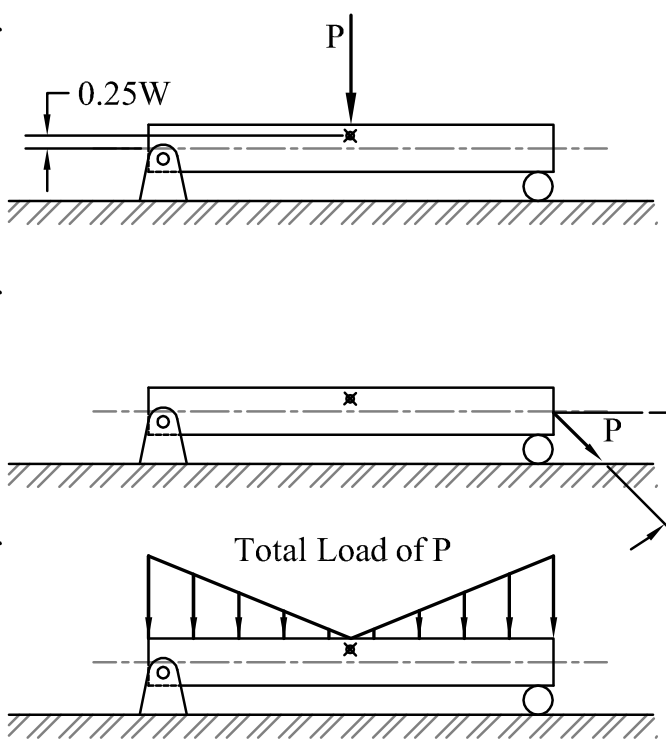

b.

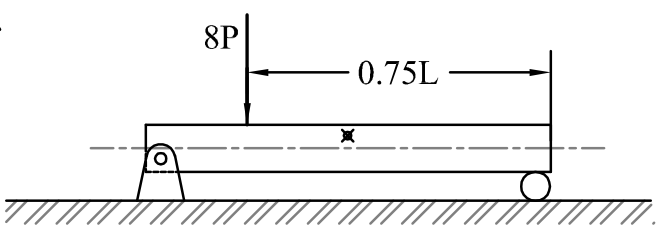

d.

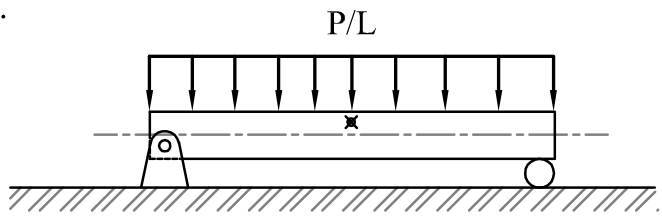

f.

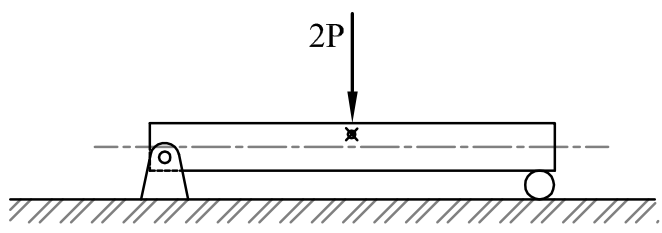

Ranking:
1)
2)
3)
4)
5)
6)

Please describe your reasoning:

What key equations or properties did you use to make your ranking? 
The figures below show identical members of length L, with identical sections, under identical loads. Each is supported by a pin on the left, and a roller on the right.

Rank these figures according to the normal stresses developed due to bending at the point indicated, from highest stress to lowest. It may not be possible to distinguish between all of the figures, so some figures may have the same ranking.

a.
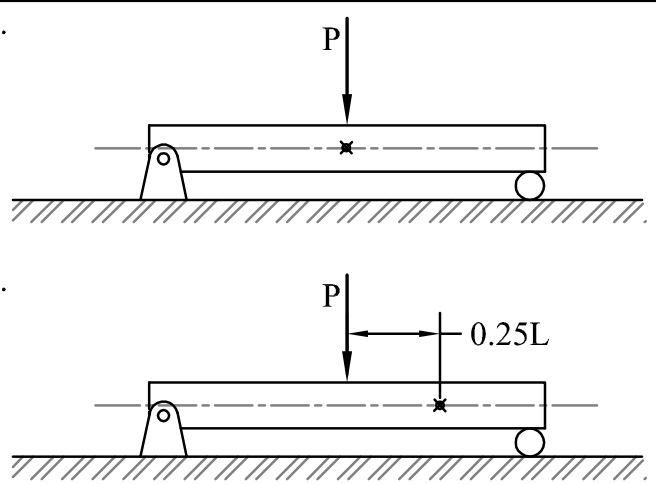

e.

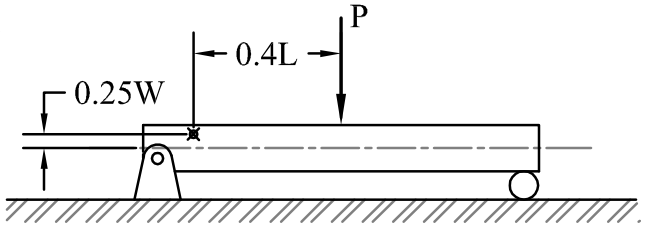

b.

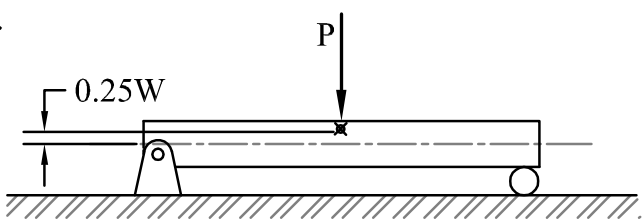

d.

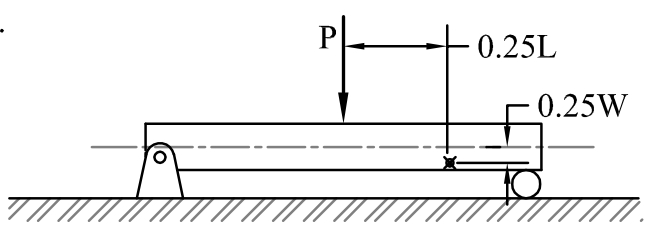

f.

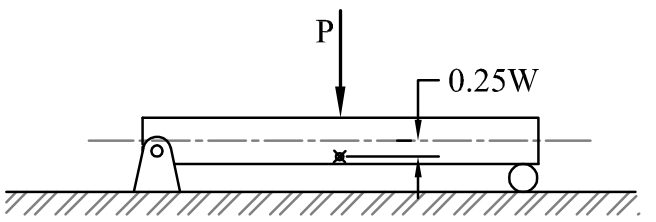

Ranking:
1)
2)
3)
4)
5)
6)

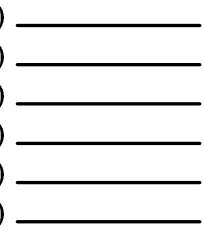

Please describe your reasoning:

What key equations or properties did you use to make your ranking? 
The figures below show a member of length $\mathrm{L}$, under a point load $\mathrm{P}$ at mid-span. Six different possible sections are shown. The dimensions that are labeled in the six figures represent differences from the typical section.

Rank these figures according to the normal stress developed due to bending at the point indicated, from highest to lowest. It may not be possible to distinguish between all of the figures, so some figures may have the same ranking.
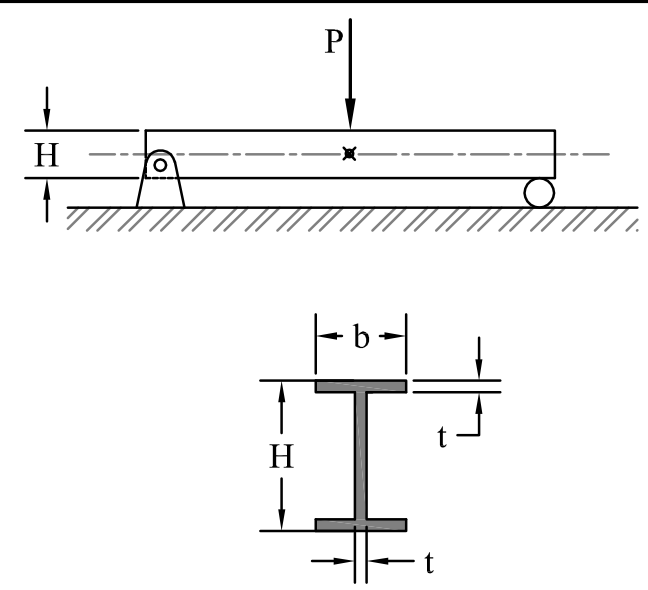

TYPICAL SECTION a.

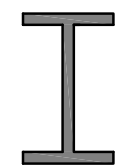

d.

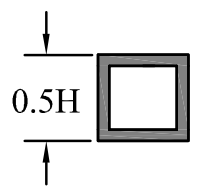

b.

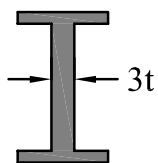

e.

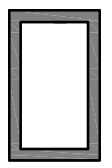

$0.5 \mathrm{H}$

c. $\frac{T}{T}$

f.

Ranking:

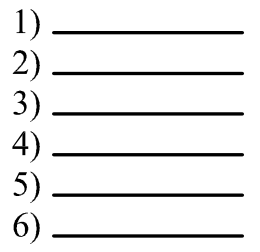

Please describe your reasoning:

What key equations or properties did you use to make your ranking? 
The figures below show a member of length $\mathrm{L}$, under a distributed load of magnitude $\mathrm{P}$ along its entire length. It is supported by a pin on the left, and two rollers on the right. Six different possible sections are shown. The dimensions that are labeled in the six figures represent differences from the typical section.

Rank these figures according to their susceptibility to local buckling in the flange, from highest to lowest. It may not be possible to distinguish between all of the figures, so some figures may have the same ranking.

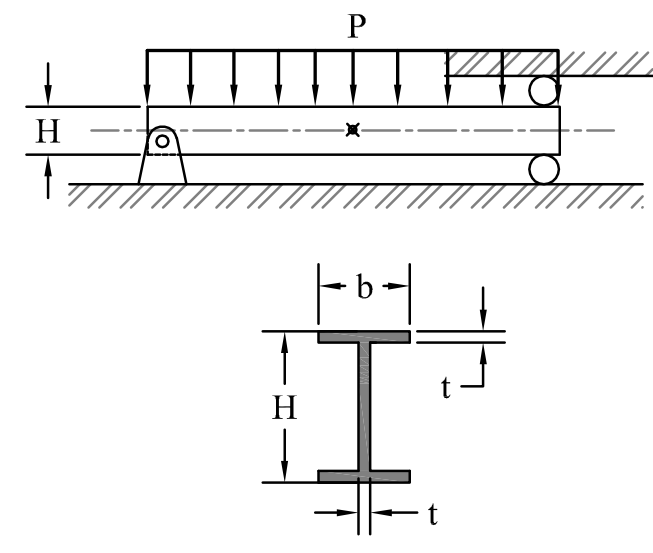

$\underline{\text { TYPICAL SECTION }}$
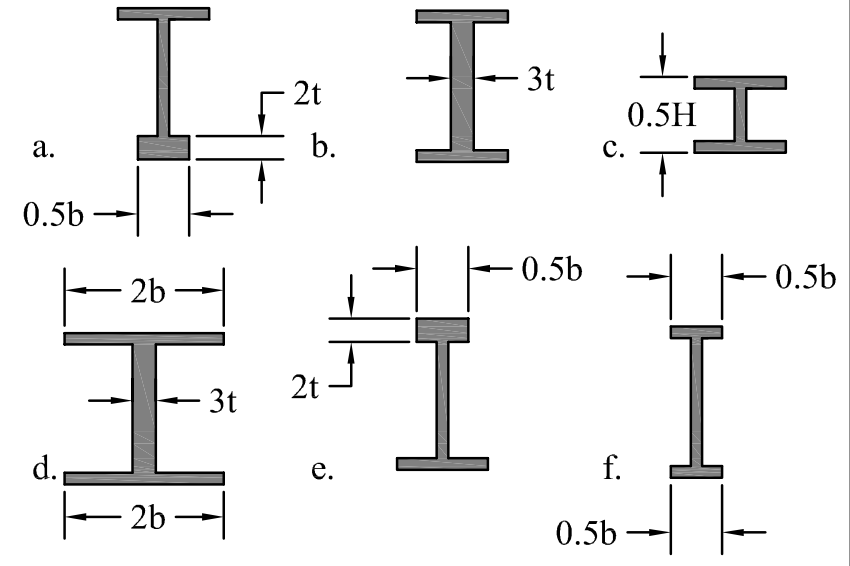

Ranking:

1)

2)

3)

4)

5)

6)

Please describe your reasoning:

What key equations or properties did you use to make your ranking? 